\title{
$1 \quad$ Assessing the Potential of Polyculture to Accelerate Algal Biofuel Production
}

2 Deborah T. Newby ${ }^{*}$, Teresa A. Mathews ${ }^{2}$, Ron C. Pate ${ }^{3}$, Michael H. Huesemann ${ }^{4}$, Todd W.

3 Lane $^{3}$, Bradley D. Wahlen ${ }^{1}$, Shovon Mandal ${ }^{2}$, Robert K Engler ${ }^{1}$, Kevin P. Feris ${ }^{5}$, and Jon B.

4 Shurin $^{6}$

$5 \quad{ }^{1}$ Idaho National Laboratory, ${ }^{2}$ Oakridge National Laboratory, ${ }^{3}$ Sandia National Laboratories, ${ }^{4}$ Pacific Northwest

6 National Laboratory, ${ }^{5}$ Boise State University, ${ }^{6}$ Univeristy of California San Diego

7 *Corresponding author. J.R. Simplot Company, 5369 W. Irving Street, Boise, Idaho, 83706,

8 deborah.newby@ simplot.com, 208-780-7011

9 Key words: Algal biofuel, algal polyculture, overyielding, culture resilience

10 ABSTRACT

To date, the algal biofuel industry has focused on the cultivation of monocultures of highly

12 productive algal strains, but scaling up production remains challenging. Algal monocultures are

13 difficult to maintain because they are easily contaminated by wild algal strains, grazers, and

14 pathogens. In contrast, theory suggests that polycultures (multispecies assemblages) can

15 promote both ecosystem stability and productivity. A greater understanding of species

16 interactions and how communities change with time needs to be developed. Ultimately a

17 predictive model of community interactions is needed to harness the capacity of biodiversity to

18 enhance productivity of algal polycultures at industrial scales. Here we review the agricultural

19 and ecological literature to explore opportunities for increased annual biomass production

20 through the use of algal polycultures. We discuss case studies where algal polycultures have

21 been successfully maintained for industries other than the biofuel industry, as well as the few 
22 studies that have compared biomass production of algal polycultures to that of monocultures.

23 Assemblages that include species with complementary traits are of particular promise. These

24 assemblages have the potential to increase crop productivity and stability presumably by utilizing

25 natural resources (e.g. light, nutrients, and water) more efficiently via tighter niche packing.

26 Therefore, algal polycultures show promise for enhancing biomass productivity, enabling

27 sustainable production and reducing overall production costs.

\section{INTRODUCTION}

Algae hold much promise as a viable feedstock for biofuels but there is still much discussion over how to make production more cost effective [1-7]. High biomass and lipid yields are

32 achievable from algae cultured under contr olled laboratory conditions at the bench scale or in 33 incubators (e.g., photobioreactors). However, cultivation in outdoor pond facilities may be the 34 only cost-effective way to produce algal biomass at the scales needed for the biofuel industry [335 9]. To date, the algal biofuel industry has focused on selecting for (or genetically modifying) algal strains that have rapid growth rates or high lipid contents in order to maximize lipid yields

$37[3,4]$. While this strategy can be effective at smaller scales and in the short term, shifting production from the laboratory to outdoor ponds raises a number of ecological challenges [10].

Monocultures are exceedingly difficult to maintain in outdoor settings, because they are easily contaminated through aerial colonization by wild algal strains, grazers, and pathogens [11-

41 13]. In terrestrial systems, the agriculture industry has had to develop multiple layers of defense

42 against such invaders (e.g. herbicides, fungicides, pesticides, genetically engineered organisms, 43 etc.) to optimize yields of monoculture crops. Because aquatic systems are readily invaded by a 44 host of microbes and invertebrates, algal crops are more susceptible to losses due to invading 
45 species. Specific interactions of concern include competition, predation (i.e., grazing pressure),

46 and pathogenic interactions. Competition for nutrients and allelopathy (chemical warfare) with

47 non-target algal strains can significantly reduce production rates and/or alter the quality of the

48 biomass produced $[14,15]$. Predation by grazers or invasion by algal pathogens can decrease the

49 stability of production by destroying mass cultures in a matter of days [16]. It has been estimated

50 that 10 to $30 \%$ of annual production in open ponds is lost due to pond crashes induced via

51 consumption of the algal crop by a contaminating grazer or invasion by a crop specific pathogen

$52[11,17]$. Additionally, these interactions can influence the temporal consistency of algal biomass

53 production and/or cellular lipid content, thereby affecting the stability of the algal culture.

54 Clearly, crop protection and management will be a critical need for maintaining predictable and

55 stable crop production for the algal biofuel industry as production begins scaling up.

In contrast to the monocultures grown for the biofuel industry, algae in natural ecosystems

57 exist in diverse multispecies assemblages [12], where species abundance can fluctuate as

58 environmental conditions change. Such changes are driven by spatial and temporal heterogeneity

59 in resources such as light and nutrient availability that can change rapidly over time and with

60 depth in the water column, creating multiple niches for species with different optimum light or

61 nutrient conditions. In addition, the landscape of biotic interactions can also vary as grazers or

62 pathogens can often be very selective for an algal strain or group of algae. When these stressors

63 affect an algal population, other algal species within the assemblage can quickly multiply to fill

64 the newly available niche. Although typically no single species in these complex natural system

65 assemblages dominates for any extended period of time, overall algal production can stay

66 relatively stable as long as nutrient concentrations are sufficient and algal species diversity is

67 maintained. 
There is much evidence from the agricultural and ecological literature that species diversity can promote both ecosystem stability and productivity [18-20]. These principles have recently been applied to biofuel production of grassland plants and algae with promising results — higher

71 diversity can lead to higher biomass and lipid production than monocultures [21, 22]. In addition 72 to providing crop protection from losses due to grazing and infection, there is evidence that algae 73 polycultures can provide a more stable crop [23]. Further, polycultures that effectively combine 74 species with complimentary traits such as for nutrient and light utilization have greater potential 75 for overyielding (i.e., higher productivity or increased biomass quality in the polyculture relative 76 to the most productive monoculture strain [24]).

77 These studies provide encouraging indications that use of algal polycultures may be an 78 effective approach to enhancing algal biomass production. Applying these principles to long79 term, larger-scale production efforts will require a greater systematic understanding of species 80 interactions and how algal communities change with time. Indeed, complex microbial 81 communities are a reality of algal biofuel production at industrial scales. However, diversity is 82 no guarantee of high productivity or stability as only a subset of species combinations display 83 these desirable properties, and only under particular environmental contexts. Identifying 84 consortia of species that consistently yield biomass with useful biochemical composition, and the conditions under which they outperform single species, is therefore a research priority.

In this review, opportunities that algal polycultures offer the biofuels industry for increasing

87 algal biomass yields are highlighted. Specifically, the basic ecological principles that support the 88 theoretical basis for increasing species diversity to increase crop stability and productivity are 89 highlighted and examples are provided of studies that have shown promise for application to the 90 industry. Recent advances in harvesting, extraction, and conversion technologies that make use 
91 of algal polycultures, and in turn make their cultivation a more viable solution than previously

92 considered, are also described. Finally, the challenges and potential for improved biomass

93 productivity and stability through implementation of a polyculture strategy are considered.

\section{ECOLOGICAL PRINCIPLES AND POLYCULTURES}

The relationship between ecological diversity and stability has been a subject of debate

97 within the scientific community [25-28]. Theory predicts a positive correlation between diversity and stability in ecological communities [29], but there has been much discussion about how these factors should be defined and quantified. Definitions for ecological stability in the literature can broadly be broken into three categories: (1) the ability to stay unchanged (constancy), (2) the ability to return to the reference state after perturbance (resilience), and (3) persistence through time, and approaches to quantifying stability vary accordingly [30]. For example, biomass productivity may be maintained as the environment fluctuates if species that decline in abundance are replaced by others with different tolerances. Simply increasing the number of species does not necessarily increase the stability of a system if species are functionally equivalent or respond to the environment in a common fashion. That is, species must respond differently to environmental fluctuations or interact in ways that cause their populations to vary asynchronously in order for diversity to enhance ecosystem stability. The species that are present and what role they play in the ecosystem (i.e., functional diversity) is at least as important in determining both ecosystem stability and productivity [22, 31]. 
114 one species will grow well $[32,33]$. Within the planktonic (i.e., free floating) algae in natural 115 aquatic ecosystems, the relationship between diversity and productivity is generally positive 116 [12], even though maximum productivity can be seen during low diversity blooms that escape 117 predation [34] which may not be sustainable over longer time periods. The algal biofuel industry 118 will be faced with the trade-off between maximum productivity and crop stability for the long119 term, sustained production of algal biomass [10].

Research has shown that polycultures can vary in productivity with respect to their respective 121 monocultures [24], but that higher productivities (i.e., overyielding) are possible with 122 polycultures [10, 23, 24, 31, 35]. Underyielding (i.e., when a polyculture yields less than the 123 average of its component monocultures) can result, for example, when a polyculture is 124 dominated by a fast-growing, low-yielding species [14, 24] or due to allelopathy, where a 125 secondary metabolite produced by one species is toxic to another [36]. In order to maximize the 126 potential for overyielding, polycultures can be assembled based on their specific traits (e.g., light, 127 nitrogen, micronutrients, etc.) to maximize biofuel industry resource use [37, 38]. Functional 128 richness, which is a measure of specific prominent characteristics (e.g., biochemical, 129 physiological, and ecological), may be more influential on productivity in phytoplankton 130 communities than species richness [31], and increased algal species richness has been shown to 131 decrease grazer survival as inedible or defended taxa may interfere with feeding on preferred 132 prey [10]. The uncertainties associated with polyculture yields highlight the need to be selective 133 in polyculture assembly.

134 In laboratory experiments, rationally designed polycultures have shown the potential to 135 outperform monocultures through overyielding [10, 33, 35, 37, 39, 40]. This is accomplished by 136 selecting species with desirable and complimentary traits that allow for more efficient utilization 
137 of light and nutrients, provide benefits towards crop protection, and/or resilience towards

138 fluctuating environmental conditions. While some rationally designed polycultures have been

139 shown to exceed productivity of monocultures in laboratory experiments, systems that utilize

140 natural polycultures have demonstrated the benefits of diverse polycultures to algae production

141 and culture stability on larger outdoor scales. For instance, a study of productivity of a

142 production pond at Sapphire Energy over a complete annual cycle found that periods of high

143 eukaryotic diversity and low prokaryotic diversity were associated with greater mean and lower

144 variance in algal biomass yield [41]. This result indicates that algal diversity enhances

145 productivity and stability, and that interactions between bacteria and prokaryotic algae drive

146 diversity and productivity in industrial systems.

147 Another example of the functional role of diversity in aquatic ecosystems is illustrated by the 148 Algae Turf Scrubber ${ }^{\circledR}$, or ATS $^{\mathrm{TM}}$, system [42]. The ATS is an engineered system using shallow, 149 pulsed water flow in a planar surface channel configuration to grow an attached mat of 150 indigenous benthic and planktonic algae in the form of "algal turf" characterized by a broad and 151 dynamic species profile [43]. Since its initial development, ATS has been exploited at both pilot 152 and multi-acre commercial scales to remove excess nutrient loading from fresh, estuarine, and 153 marine surface water bodies [44-48] and from agriculture and municipal waste streams [49-53].

154 Pilot-scale ATS annualized biomass productivities approaching $20 \mathrm{~g} \mathrm{~m}^{-2} \mathrm{~d}^{-1}$ (AFDW) have been 155 reported, but little work has been done thus far to optimize ATS biomass productivity and quality 156 [43]. A rotating system analog to ATS is the rotating algal biofilm reactor (RABR) [54]. The 157 indigenous polyculture in ATS systems has demonstrated stability and resilience over prolonged 158 periods of operation, but biomass productivity and quality of harvested material (i.e., content 159 profile of carbohydrates, proteins, lipids, other organics, and ash) has varied widely with 
160 conditions and details of cultivation and harvesting operations in water treatment applications.

161 Improvements in these system properties may be achievable with a more intentional design of

162 the cultivated algal community. Here we outline areas of opportunity for algal polyculture

163 design.

164

\section{$165 \quad 2.1$ Light}

Photosynthesis is an inefficient process, in part because only a small portion of solar light

167 (blue at $\sim 430 \mathrm{~nm}$ or red at $\sim 660 \mathrm{~nm}$ ) is absorbed by chlorophyll a, the principal photosynthetic

168 pigment in algae, and because much of the available light is quenched or dissipated before it can

169 be used for photosynthesis. Commercial algal production rates only attain $\sim 1-2 \%$ solar to product

170 energy conversion efficiency, which corresponds to $\sim 5-25 \%$ of the theoretical maximum

171 productivity of photosynthesis. Stephens et al. (2010) estimated that a $2 \%$ photosynthetic

172 conversion efficiency supports practical annual yield of 20,000 L algal oil per hectare with

173 current outdoor mass cultivation technology and available strains. They envisioned that much

174 higher oil productivity (e.g. 60 to $100,000 \mathrm{~L} \mathrm{ha}^{-1}$ year ${ }^{-1}$ ) could be attainable, assuming a

175 maximum photosynthetic conversion efficiency of $10 \%$ [57]. Increasing light use efficiency has

176 therefore been recognized as an area for significant improvement in biomass production. Several

177 strategies to increase light use efficiency have been proposed, including genetically modifying

178 algae photosynthetic apparatus to reduce scatter and dissipation of photons or pulsing light/dark

179 cycles in algal photobioreactors.

180 Algal polycultures have the potential to utilize light resources more efficiently than

181 monocultures if they include species of a variety of taxonomic groups [58, 59]. Different algal

182 taxa have evolved a suite of accessory pigments which are capable of absorbing light across a 
183 range of wavelengths [55] (Table 1). For example, while chlorophyll a is ubiquitous among

184 algae, other pigments have a more limited distribution and function as accessory photosynthetic 185 pigments.

186 


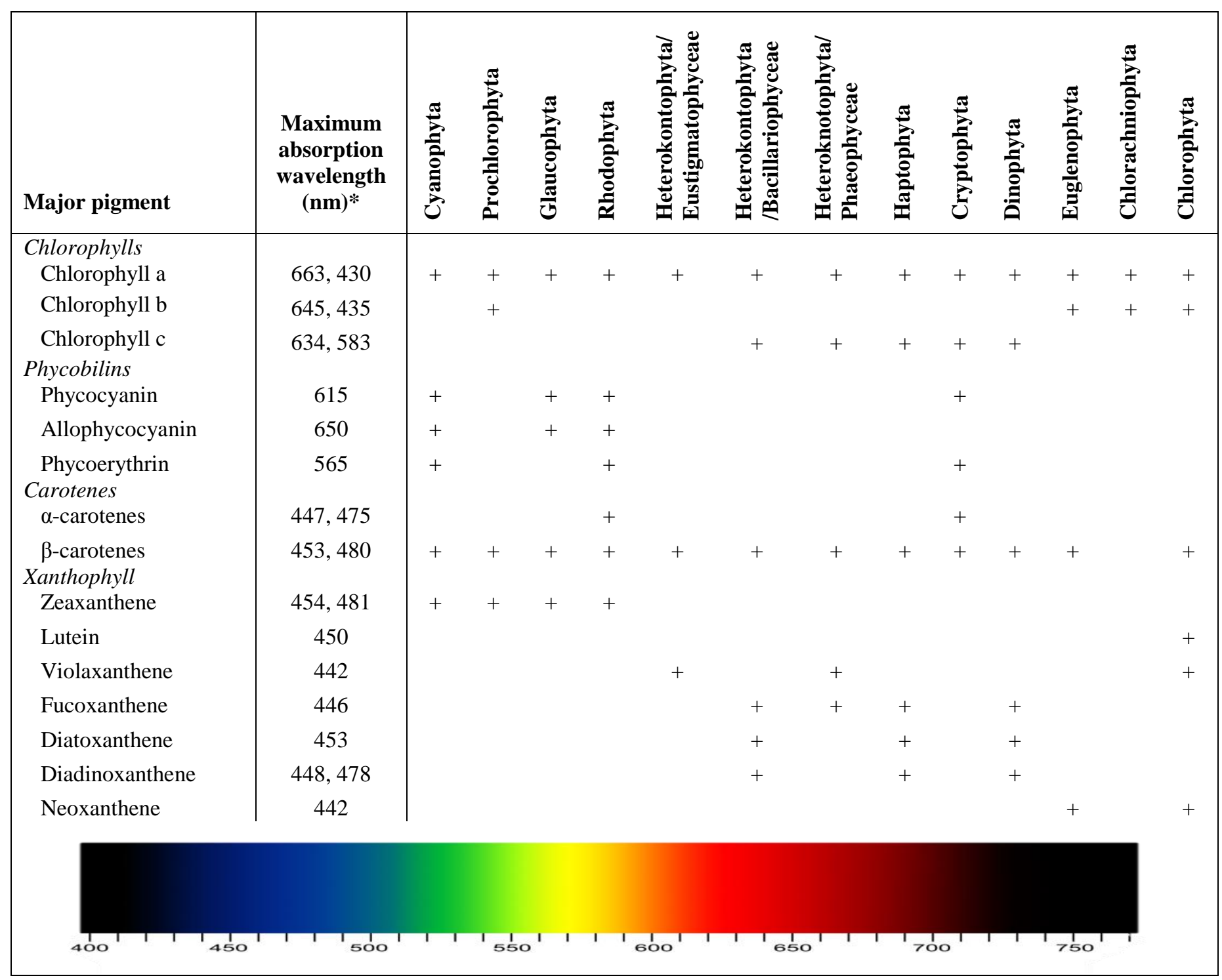

$+=$ presence of pigments

*Absorption of pigments dissolved in acetone. 

competition among algal species that absorb different spectra of light. Indeed, bench scale experiments have shown that the inclusion of algae from different functional groups (i.e. green

195 algae, golden algae, cyanobacteria, and diatoms) increased not only light use efficiency, but also lipid yield [31, 61]. Algal polyculture design can benefit from these studies, especially when

197 considering situations where light may be limiting (e.g. off season, off peak times during the day, with depth in dense algal culture etc.).

\subsection{Water and Nutrient Resources}

Scaling up algal biomass production will put increasing demands on our nation's already strained water and nutrient supplies[62,63]. While algae need relatively low concentrations of nutrients and water, large scale production will compete with the agriculture industry for both 204 irrigation and fertilizer resources, especially in areas where freshwater resources have reached 205 the point of full allocation. The utilization of wastewater resources that are rich in nitrogen and 206 phosphorus can supplement a portion, or completely replace, traditional fertilizer and water 207 requirements may help significantly reduce algal production costs [64-67].

It is generally accepted that optimal algal biomass production requires nutrients at a molar ratio of $\mathrm{C}_{106}: \mathrm{N}_{16}: \mathrm{P}_{1}$ (the Redfield Ratio) [68], suggesting that of these three major nutrients,

210 nitrogen and phosphorus should become limiting before carbon. However, in commercial scale 211 algal cultivation in nutrient-rich environments, dissolved carbon in water is usually the limiting

212 factor for growth as carbon assimilation by algae is higher than the rate $\mathrm{CO}_{2}$ diffusion from air 213 into water [62, 69-71]. Further, several studies have shown that deviations from Redfield 214 stoichiometry can be due to various factors including habitat and nutrient use efficiency (the 
215 number of moles of carbon fixed into algal biomass per mole of cellular N or P) [72]. This

216 plasticity in stoichiometry of algal biomass suggests that demands of $\mathrm{N}$ or $\mathrm{P}$ for algal biofuel

217 ponds should be calculated based on pilot-scale or commercial-scale operating under varying

218 environmental condition.

219 Algal diversity enhances resource use efficiency. More than 3,000 phytoplankton samples 220 analyzed from Scandinavian lakes and the Baltic Sea showed that phytoplankton diversity and 221 nutrient use efficiency were positively correlated and both community composition and nutrient 222 use efficiency were stabilized by diversity [73]. Species combinations with more divergent traits 223 may use resources in complementary ways, and produce more biomass than even their most 224 productive species [24]. Cardinale (2011) argued that species rich communities take greater 225 advantage of the niche opportunities in an environment, and this allows diverse systems to 226 capture a greater percent of available nutrients [74]. Fertilization with nutrients often reduces 227 algal diversity by eliminating the potential for niche partitioning, leading to a system where only 228 one resource (usually light) is limiting to growth [74, 75]. Spatial and/or temporal heterogeneity 229 created by changing nutrient stoichiometry (N:P ratio) in different patches of algal culturing 230 units influences the relative fitness of species across patches, allowing for spatial niche 231 differentiation to generate complementary resource use [76].

232 A number of investigations have demonstrated the utility of wastewaters for algal cultivation 233 in both mono [77-79] and polycultures [44-54, 77], with the latter typically demonstrating higher 234 yields and/or more stable productivity. Similar to nutrient stoichiometry and light availability, 235 the full utilization of the complex niche space in wastewater streams will be facilitated by 236 incorporating polycultures as wastewaters commonly contain a complex combination of factors 237 that can negatively influence cultivation of individual algal strains. Although, potentially viable, 
238 intentional polyculture constructs designed as a

239 function of wastewater characteristics have yet

240 to be demonstrated in the literature. However,

241 strategies that cultivate naturally selected

242 polycultures, as described for the ATS systems,

243 are currently being employed for wastewater

244 treatment [44-54] and have the potential to be

245 scaled to achieve large-scale biofuel production.

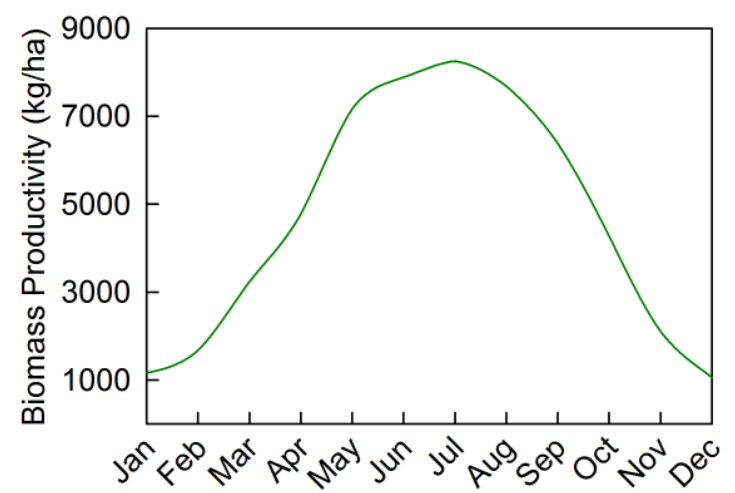

Figure 1. Modeled long-term mean monthly biomass production Chlorella sp. 1412 in Sarasota FL. [Coleman et al., 2014]

247

\subsection{Temperature Variation}

The effect of algal diversity on the stability of community biomass production in a variable environment depends on whether populations fluctuate synchronously or out of phase with one another [80]. The degree of synchrony in population dynamics depends on niche differentiation in terms of whether species respond similarly or differently to environmental conditions. For instance, if all species grow better at higher temperatures, then all populations will increase in the summer and decline in the winter [81]. Alternatively, if species compete for resources and differ in their response to the physical or biological environment, then decline in one species should be compensated directly by rise in another, maintaining community biomass. Ecological engineering should aim at identifying combinations of species that maximize asynchrony in population dynamics to ensure stable production and maintain resilience in the face of climate and contamination variations.

Although many variables affect the productivity of outdoor cultures, temperature and light intensity may be the most important [82]. Algal raceways, such as those used for algae biofuel 
261 production, are particularly vulnerable to temperature variations in the spring and fall [83] as

262 well as other climatic controls such as precipitation, solar radiation, humidity, and wind that also

263 exhibit seasonal patterns [84]. Seasonal temperature variation results in suboptimal growth

264 temperatures, which negatively impacts biomass productivity. Figure 1 depicts an example of

265 typical variation in productivity over a year using a biomass growth model, where seasonal

266 temperature variation is a key variable [85]. Productivity during spring (March through May) and

267 fall (September through November) are estimated to be approximately $47 \%$ and $34 \%$ lower,

268 respectively, than during peak summer months (June through August) [85].

269 Engineering and biological solutions for minimizing the impact of seasonal and diurnal

270 temperature variation have been pursued, including novel raceways designs (e.g., ARID

271 raceway) $[83,86]$ and algal crop rotation with cold-tolerant strains $[87,88]$. Effective strategies

272 for optimizing the annual yield of ponds will certainly include both engineering and biological

273 solutions, as the temperature-dependent growth rates of algal species vary considerably among

274 strains [89]. Generally, algae growth rates increase with rising temperatures until they reach an

275 optimal growing temperature around 20 to $25^{\circ} \mathrm{C}$ [89], at which point, further increases in

276 temperature are accompanied by decreases in growth rate. After $30^{\circ} \mathrm{C}$, growth rates decrease

277 dramatically for most strains currently investigated for biofuel production. Butterwick et al.

278 found large inter-species differences in the ability of algae to grow at low temperatures (i.e., less

279 than $10^{\circ} \mathrm{C}$ ) [89]. Their results indicated that some strains were better suited for cool seasonal

280 growth and that adopting a crop-rotation approach to enhance productivity seemed reasonable. In

281 addition, Thomas et al. (2013) showed that the temperatures for optimum growth ranged from

$28230^{\circ} \mathrm{C}$ to less than $5^{\circ} \mathrm{C}$ for algae isolated from across a broad latitudinal gradient [90]. Although

283 crop rotations with cold tolerant algae have the potential to normalize productivity over an 
284 annual period by extending the seasonal window for cultivation, crop rotation may be best suited 285 for winter when temperatures are consistently suboptimal and a productive cold-tolerant strain 286 could thrive. In the absence of crop rotation, a diverse polyculture composed of strains with 287 differing temperature optima would be able to respond quickly to fluctuating daily temperatures 288 during the spring and fall. Whereas a monoculture, limited to the adaptability of a single strain, 289 would be less productive.

Litchman et al. described three ways in which natural phytoplankton communities respond to 291 changing environmental conditions, each of which have important implications to how algae 292 could be effectively cultured for biofuel production [91]. First, when faced with changing 293 conditions, such as a cooler temperature, a species can adapt to the new conditions as long as the 294 conditions are within a tolerable range through either phenotypic plasticity or genetic changes.

295 Algae with a broad thermal tolerance will be better able to adapt to seasonal fluctuations. For the 296 monoculture cultivation model to be successful for algal biofuel production, a commercial strain 297 must be capable of growth at both high temperatures in the summer and the lower, fluctuating 298 temperatures experienced in the spring and fall. A second mode of response to changing 299 conditions, observed by Litchman et al. in natural communities, occurs when a dominant species 300 fails to adapt to new conditions and instead is replaced by a species better suited for the current 301 conditions [91]. This change in species abundance is termed species sorting. As diversity within 302 a culture increases, the probability that at least one member of the community will be better 303 suited for the current environmental conditions and the biotic interaction landscape increases. A 304 final mechanism of species adaptation to changing conditions is through natural selection, where 305 the new conditions select for mutations, horizontal gene transfers, or recombination events that 306 confer some competitive advantage. Ras et al. considered this third mechanism for adaptation to 
307 be unlikely in the case of algae biofuels due to the rapid temperature fluctuations that shallow

308 algal ponds are likely to undergo during the spring and fall. The fluctuating conditions would not

309 prevail long enough to select for generational adaptation [92]. A polyculture approach to algae

310 biofuels could provide sufficient diversity to minimize decreases in growth rate and productivity

311 due to fluctuating temperature.

312 A recent study investigated the response of monocultures and polycultures to daily

313 fluctuating temperatures [93]. The experiment was carried out by acclimating 15 monocultures to

314 three temperatures: 12,18 , and $24^{\circ} \mathrm{C}$ for a 2 -week period. Mixtures with varying species richness

315 (i.e., 2, 3, 6, 9, and 12 strains) were assembled from the same 15 strains and were incubated at

316 the same constant temperatures. After 14 days, Phase II of the experiment began to determine the

317 effect of fluctuating temperatures on culture productivity. During this phase, the culture

318 temperatures were each increased by $4^{\circ} \mathrm{C}$ for a period of 7 hours. The temperature oscillations

319 were repeated daily for 7 days. Species richness had a positive effect on growth rate at each

320 temperature level (i.e., 12,18 , and $24^{\circ} \mathrm{C}$ ). Overyielding was observed for both the constant and

321 fluctuating temperature environments, with the strongest effect being observed at $18^{\circ} \mathrm{C}$.

322 Overyielding was attributed to complementary effects, where increased diversity resulted in a

323 more efficient utilization of resources through resource partitioning among species with different

324 temperature-growth profiles. The authors did not find evidence to support the selection effect or

325 the emergence of a dominant strain. This study emphasizes the importance of biodiversity in

326 determining a phytoplankton community's response to varying temperatures and indicates that

327 polycultures could greatly improve annual algal biomass productivity over a monoculture. 


\subsection{Synergistic and/or Probiotic Relationships}

331

Algae and bacteria have long been known to grow in close association with one another. This is particularly evident in marine systems where nutrients are scarce and limit growth. For example, iron availability often limits photoplankton primary production due to iron's poor solubility at near neutral $\mathrm{pH}$ [94]. Mutualistic and commensalistic interactions among bacteria and algae have been shown to promote algal growth by increasing Fe availability $[95,96]$. As a result of bacteria-algae associations, algal growth can often be sustained at low Fe concentrations that would not support growth in the absence of associated bacteria [95]. Bacteria overcome iron limitation by secreting siderophores, small iron-chelating organic molecules, to increase the solubility of iron [97]. Siderophore secreting bacteria in close association with microalgae under photoautotrophic conditions have been found to enhance iron uptake in algae by 20 fold [96]. Associations between bacteria and algae can improve nutrient utilization and promote algal productivity, suggesting that polyculture production may benefit from community constructs that incorporate more than just photosynthetic community members.

Some algae depend on prokaryotes for vitamins essential for growth. Croft et al. found that $50 \%$ of the microalgae surveyed are vitamin $\mathrm{B}_{12}$ auxotrophs and require an external source of cobalamin for growth $[98,99]$. Cobalamin, produced only by prokaryotes, is essential to the production of the amino acid methionine in about half of microalgal species. Those that do not require vitamin $B_{12}$ (about half), utilize a different enzyme that performs the same function in the absence of vitamin $\mathrm{B}_{12}$ [98]. Microalgae may obtain the necessary cofactor from bacteria either directly or indirectly by scavenging from the environment [98-101]. In exchange for the essential cofactor, microalgae support the bacteria with photosynthate $[98,99,101]$, this exchange is an example of how bacteria and algae mutually benefit from their association. 
Phytohormones are a class of small molecules that regulate plant growth and development 354 and include the plant hormones indole-3-acetic acid (auxin), cytokinin, gibberellin, ethylene, and 355 abscisic acidin; this is in addition to brassinosteroids, jasmonic acid, and salicylic acid. The 356 effect of the addition of exogenous phytohormones to Chlorella cultures has been a topic of 357 active research for several decades. Addition of a wide variety of phytohormones to Chlorella 358 cultures impacted growth rate and the concentration of cellular constituents (such as chlorophyll 359 carotenoids, proteins, and nucleic acids) (for review see [102]). The phytohormones that 360 displayed positive effects on Chlorella growth include indole-3-acetic acid (IAA). Bacterial 361 species, such as Azospirillum brasilens and Azospirillum lipoferum, that produce IAA enhance 362 the growth of microalgae in co-cultures and when co-immobilized in alginate beads with 363 Chlorella [103]. Mutant strains of Azospirillum sp. that were defective for the production of IAA 364 did not enhance the productivity of the algae grown in co-culture but the wild-type, growth365 enhancing, phenotype could be rescued through introduction of exogenous IAA into the mixed 366 cultures [104].

Other algal bacterial interactions are less well characterized. A number of bacteria have been 368 co-isolated with microalgae from natural sources or from xenic laboratory cultures. These 369 bacteria tend to group phylogenetically with the Alphaproteobacteria, Gammaproteobacteria and 370 the Cytophaga-Flavobacterium-Bacteroides cluster [105-107]. Park et al. (2008) demonstrated 371 that the addition of Brevundimonas sp, which is isolated from xenic Chlorella ellipsoidea 372 cultures, to axenic $C$ ellipsoidea cultures results in improved algal growth [108]. The bacteria 373 grew in tight association with the algae surface in the so-called phycosphere; however, the 374 molecular basis of the growth-promoting effect has yet to be determined. Modest growth 375 enhancement was also demonstrated for Chlorella sorokiniana in co-culture with a strain of 
Microbacterium trichotecenolyticum, which was originally isolated from a xenic laboratory culture [109].

In nitrogen-limited areas of the open ocean, N-fixing cyanobacteria can have symbiotic relationships with other algae (e.g. diatoms, green algae) [110-112]. The benefit for either partner was characterized in a prymnesiophyte-cyanobacterial symbioses [113]. The prymnesiophyte receives fixed $\mathrm{N}$ in exchange for transferring fixed carbon to the cyanobacteria, Candidatus sp. Currently there is no report available that employs an algae-cyanobacterial symbiosis for mass culture of algae. This strategy may provide a free source of $\mathrm{N}$ to cultivate algae and prevent down-stream pollution of water bodies by minimizing fertilizer demands.

\subsection{Biomass Quality}

Biofuels can be produced from a great variety of algal feedstocks and depending on the origin and quality of the feedstock, the properties of the produced fuel can vary. For example, different strains of algae and cyanobacteria can vary widely in their relative lipid, carbohydrate, and protein content. Further, each algal strain has the ability to regulate their metabolism in response to environmental conditions. Nutrient limitation has been found to lead to lipid accumulation in a number of microalgal species $[114,115]$. In particular, $\mathrm{N}$-starvation suppresses protein synthesis in algae, so that the carbohydrate formed by photosynthesis is preferentially channeled to making lipids [116]. Nitrogen deficiency also results in the biosynthesis of lipid enriched in saturated and mono-unsaturated fatty acids [117]. Temperature also has a major effect on the fatty acid composition of algae with low temperatures typically inducing the formation of unsaturated fatty acid in algae [116]. 
Biodiesel is produced by transesterification, where triglyceride lipids are transformed into

399 fatty acid methyl esters. The properties of biodiesel are mainly determined by fatty acid

400 unsaturation and chain length [118]. Biodiesel with a high degree of unsaturated fatty acid

401 exhibits better lubricity and cold-temperature flow properties [119], but oxidative stability, heat

402 of combustion and ignition quality (measured by the cetane number) decreases with unsaturation.

403 While no single fatty acid is ideal for all fuel properties, a good compromise can be achieved by

404 growing multiple species with different fatty acid properties.

405

The specific species and/or strain structure of polycultures may also affect the quality of the

406 algal community biomass. For example, an experiment testing all possible combinations of six

407 different algal species, where strains were selected based on known carbohydrate production

408 potentials, had six polyculture treatments that resulted in overyielding in the estimated total

409 annual carbohydrate production by 1.5 to $30 \%$ [120]. Importantly, in this work not all

410 polyculture constructs with equal diversity levels resulted in overyielding, as also noted

411 elsewhere $[10,24]$. These findings suggest that species richness alone is not predictive for

412 determining the potential overyielding of polycultures in terms of total biomass or biomass

413 quality. Rather, the structure of the algae community (i.e., specific species or strains present,

414 richness, and distribution of each species) influences net productivity and quality metrics.

415 Suggesting that polyculture strain selection should be influenced by quality characteristics and

416 combined with strategies that result in greater stability and resilience to contaminant invasion to

417 tailor the quality of the polyculture biomass yield.

418 


\subsection{Crop Protection}

422

423

424

425

426

427

428

429

430

431

432

433

434

435

436

437

One of the primary challenges for large scale production of algal biomass is the negative biotic interactions that limit algal population densities, productivity rates, and biomass yields $[16,121]$. Grazing by rotifers, infection by fungal and bacterial pathogens $[122,123]$, and competition from invasive algal species can affect overall crop yield through the reduced quantity and/or quality of biomass [124]. Therefore, successful large-scale production of algal biofuels will likely require a holistic and broad-spectrum approach that parallels traditional agricultural techniques, whereby invasive weeds and insects are controlled through mechanical, chemical, and biological means. Increasing the species and strain diversity of an algal crop has the potential to reduce the effect of biotic contaminants on algal productivity and potentially minimize the necessity of mechanical and chemical controls on contaminants $[10,125]$.

While the overall impact of predation and pathogens to large-scale algal biomass production has not been reported on an annual basis, epidemics, grazers, and wild competitors have all been implicated in crashes of cultivated algae. Importantly, mass cultures can be destroyed within days of invasion $[16,121]$, therefore controlling contaminants is a critical need for algae biofuels to reach their potential [16]. Mitigating crop losses can have a substantial impact on overall algal yields and on costs from reseeding ponds that have crashed due to grazing and/or infection.

Polycultures that contain strains with a wide range of cell diameters and different shapes (which affect feeding by predators) may dampen the impact of infection or predation, thereby imparting greater stability. Similarly, polycultures may contribute to increased annual productivity by providing stability during periods when predators or pathogens are most active [126]. In the case of the benthic polyculture assemblages cultivated in engineered systems such as $\mathrm{ATS}^{\mathrm{TM}}$, the algal community's diversity, productivity, and stability depend on the complex 
444 interdependencies of the colonization processes. These processes involve filamentous species

445 capable of forming attachments to the $\mathrm{ATS}^{\mathrm{TM}}$ system floway substrate in cohabitation with both

446 attached, solitary, and unattached planktonic species that reside within the algal mat matrix [43].

447 In such systems, modification of the selected physical aspects of system design and operation

448 (such as floway substrate material, texture, and the hydrodynamics of the pulsed, turbulent water

449 flow) will also have an impact on the colony's species diversity profile and collective dynamic

450 biological performance in terms of culture stability and productivity $[44,127]$.

451 Sustained production of the algal monoculture has been successful for only a few strains of

452 extremophiles such as Spirulina and Dunaliella, where conditions (such as high salinity and $\mathrm{pH}$ )

453 provide protection from predation; however these operating conditions are not always practical

454 or consistent with high productivity. Pond crashes are a major threat to algal biofuels; therefore,

455 crop protection strategies should be considered a high priority research area. Park et al. (2011)

456 report that within a period of 3 months, their attempts to grow algal monocultures in outdoor

457 ponds failed due to contamination [66]. At an industrial scale, Sapphire Energy's test facility has

458 also demonstrated the vulnerability of algal strains to invasion by contaminating microorganisms

459 and has used real-time polymerase chain reaction to track invasion by a contaminant [10]. Pond

460 crashes are a significant threat to algal biofuel production and can occur rapidly, with referenced

461 rates of predatory consumption of algae on the order of 200 algal cells min $^{-1}$ rotifer $^{-1}$ [128] and

462 with the high potential of complete decimation of a culture [129]. Accordingly, investments have

463 been made to develop technologies to assess shifts in the microbiome in an attempt to

464 predict/prevent pond crashes [128].

465 Population diversity has been shown to dampen the impacts of both predation and parasitism

466 [130]. The persistent negative effects of rotifers have been observed for monocultures, whereas 
467 polycultures were more resilient following biological perturbation, specifically rotifer addition

468 [23]. Consortia may be more resistant and/or resilient to invasion by other species for a variety of

469 reasons, including diversity of algal size, presence of silica frustules (diatoms), specificity of

470 predator-prey dynamics [23, 131, 132], and production of compounds that inhibit predators and

471 pathogens [133]. Interference by unpalatable or defended taxa may reduce grazer consumption

472 and indirectly benefit undefended taxa through associational defense. In addition, the dilution

473 effect suggests that a diverse host community may slow the spread of invasions [134, 135].

474 Dense monocultures may be uniquely vulnerable to the spread of specialized pathogens.

475 However, disease agents that encounter a range of potential hosts varying in competency may

476 spread more slowly, resulting in weaker epidemics and smaller impacts on host populations.

477 A handful of recent polycultures studies, focused on algal biofuel production, report new

478 developments relating to crop protection. Corcoran and Boeing (2012) assessed combinations of

479 two groups of phytoplankton with differing growth rates and susceptibility to grazing [23]. They

480 found that productivity was driven primarily by species combination, while species richness was

481 more important in terms of stability. Shurin et al. (2013) reports the potential of polycultures to

482 increase algal biofuel based on nutrient load, ecological trade-offs, and predator susceptibility

483 [10]. They randomly assembled and tested communities consisting of 1, 2, 5, or 10 species of

484 phytoplankton (representatives from Chlorophyta, Cyanophyta, Bacillariophyta, and

485 Heterokontophyta), generating 31 unique diversity and composition treatments. These treatments

486 were challenged by the addition of a grazer. On average, polycultures were found to be about

$48729 \%$ more productive than the mean component species in a monoculture, but they were about

$48819 \%$ less than the most productive species alone. However, one exception comprised of two

489 cyanobacteria and three chlorophytes produced more biomass than any other combination and 
490 two times_more than any monoculture. Both community richness and species composition were 491 found to influence biomass productivity. In addition, polycultures, in general, utilized more 492 diverse nutrients and better resisted grazers. However, the most productive polycultures were not 493 necessarily the most resistant to predation, demonstrating that it may not be possible to optimize 494 for all desired population characteristics simultaneously. Furthermore, there are examples in the 495 literature where, depending on the species present, polycultures were less productive when 496 compared to monocultures $[10,14,136]$. This again emphasizes that strain composition is a 497 critical parameter and that not all polycultures are expected to out-perform monocultures. 


\section{CONVERSION}

Until recently, the primary conversion pathway for algal biofuels involved the production and extraction of a high lipid content algal monoculture followed by lipid upgrading [3-7],

501 although challenges remain with lipid extraction from wet biomass [140] required to avoid the 502 energy and environmental costs associated with drying the biomass. The combination of 503 monoculture cultivation approaches and focus on lipid production as the dominant pathway to 504 fuels also face challenges with respect to the maintenance of robust, long-term culture health and 505 productivity $[16,17,66,121-124,128,129]$ and sustainable scale-up from the standpoint of 506 resource demand and utilization $[62,63,141]$. Polyculture approaches can potentially help 507 address these challenges. However, polyculture algal consortia also face technical challenges in 508 terms of downstream processing (e.g., harvesting, dewatering, and extraction and/or conversion 509 to fuels). When compared to monocultures, polycultures tend to have lower content of neutral 510 lipids and varied content and ratios of major organic biochemical constituents (i.e., proteins, 511 carbohydrates, lipids, and other compounds). Harvested polyculture biomass can also have 512 larger inorganic ash content (a combination of biogenic and exogenous ash material) that 513 depends on the algae species profile and the conditions under which it is grown and harvested.

514 This includes water quality (e.g. use of clean vs. wastewater with silt, sand, and other particulate 515 content), water chemical composition (e.g., fresh vs. saline with salt content), cultivation and 516 harvesting approaches used and cultivation location (which can lead to greater ash content from 517 environmental contamination). For example, the presence of macroalgae (typically high in ash) 518 or diatoms (containing silica frustules) in harvested polyculture material can add biogenic ash, 519 while additional exogenous ash can be introduced through the environmental contamination in 520 open cultivation systems and from salts in saline water systems, as noted earlier. To be clear, 
521 monocultures otherwise grown in relatively clean fresh or saline water can also have elevated ash

522 content approaching or greater than $20 \%$, on a dry weight basis, depending on species (e.g.

523 diatoms vs. green), water conditions (fresh vs. salt), and cultivation system and location factors

524 (e.g. open systems in arid regions subject to contamination from atmospheric dust, blowing sand, 525 etc.) $[142]$.

526 Recent technologies for the processing and conversion of whole algal biomass (e.g.,

527 hydrothermal liquefaction - HTL and the combination of biochemical conversion with HTL)

528 allow for relatively efficient conversion of all organic constituents of the biomass (lipids,

529 carbohydrates, protein, and other) into fuel intermediates regardless of the neutral lipid content

530 of the algae. HTL mimics natural geologic processes that converted ancient plant material to

531 petroleum. HTL uses heated, compressed water to dissolve organic compounds, and its elevated

532 ion production can accelerate the acid-catalyzed, hydrolytic decomposition of algal

533 biomacromolecules [143, 144]. Output from HTL typically consists four separable fractions

534 [144-159]: (1) an oily biocrude that can be upgraded using refining techniques to produce

535 hydrocarbon fuels, (2) an aqueous co-product (ACP) phase, (3) a solid residue that may be

536 suitable for use in soil amendments, absorbents, catalysts, and asphalt [145-150], and (4) a

537 possible gaseous phase, depending on feedstock and processing conditions [152]. The ACP can

538 be further processed to produce additional energy products and process heat $[150,152,153]$,

539 hydrogen for co-processing $[152,153,160]$, and the capture and recycling of water, nutrients $(\mathrm{N}$,

$540 \mathrm{P}$, etc.) and $\mathrm{CO}_{2}[143,150,152,153]$. The HTL process is well suited to the conversion of wet

541 algal biomass that has been partially dewatered to about 10-20\% solids content, with the

542 feedstock itself providing the water needed for processing. This avoids the severe energy input

543 costs and environmental penalties associated with having to dry the biomass, and also provides a 
544 conversion process potentially capable of effectively dealing with variations in the organic

545 content (lipids, carbohydrates, proteins, etc.) of polyculture biomass. This has made it possible

546 to re-consider the use of polycultures as a viable option for biofuel production, regardless of the

547 neutral lipid content of the biomass $[145,161,162]$. Elevated non-organic ash content in the wet

548 algal biomass feedstock will be an issue for HTL, in that its presence adds material loading to the

549 processing stream that does not contribute to fuel production, requires additional system

550 processing capacity (and associated capital and operating costs) to accommodate, and reduces

551 the effective fuel product yield per mass unit of material processed [140, 163-168]. Ash content

552 can also contribute to corrosion or fouling of HTL systems and components, depending on the

553 type and amount of ash, the processing conditions, and the type of materials used in the

554 equipment [153-159]. Varying degrees of ash content impacts on HTL processing have been

555 only sparely reported in the literature [153-159], however no systematic investigation has been

556 done thus far to better quantify the impacts and establish practical limits for cost-effective HTL

557 processing [169]. Ash impact mitigation approaches include taking steps to possibly reduce the

558 introduction of exogenous ash content into the harvested material in the first place, and applying

559 pretreatment to the wet harvested material to reduce the existing ash content prior to HTL

560 processing $[157,163-166,168]$.

561 Whole processing of the entire biomass via HTL is a promising technology because of the

562 relatively high yields of biocrude possible from the non-ash organic content of the biomass (i.e.,

563 up to 66 wt \% in some cases) [151]. Roberts, et al. (2013), Chen et al. (2014), and Pate, et al.

564 (2015 and 2016) used polyculture algae biomass produced from wastewater and contaminated

565 surface water as HTL feedstock and demonstrated that the bio-crude oil yields and energy

566 recovery were comparable to those converted from monoculture microalgae $[145,147,164$, 
168]. In typical one-step direct hydrothermal liquefaction process some portion of valuable polysaccharides, reducing sugar, and protein are decomposed into bio-gas and biochar through hydrolysis, dehydration, and polymerization. The Chen group from Washington State University suggested to use sequential hydrothermal liquefaction process in which sugar and protein were separated first at a lower temperature, and the remaining biomass was then converted to bio-oil at a higher temperature [170]. More recently, Sandia National Laboratories (SNL) researchers have shown promising work on tandem biochemical and HTL processing of whole polyculture algal biomass, including algal turf, to allow for high-efficiency conversion of the carbohydrate and protein fractions to ethanol and isobutanol, extraction of neutral lipids, and HTL processing of remaining organic residue $[163,171]$.

\subsection{Downstream Processing of Polyculture Algal Biomass: A Case Study}

SNL has recently demonstrated that acid pretreatment of both raceway pond monoculture algae biomass and polyculture algal turf biomass is sufficient for solubilization and hydrolysis of about $90 \%$ of the carbohydrate fraction to monomeric sugars. The dominant sugars that were recovered from this process include mannitol and glucose. The protein content of the biomass was approximately equal to the total quantity of carbohydrates. Together, these biochemical fractions account for approximately $75 \%$ of the mass balance of the total AFDW biomass. SNL also demonstrated that the combination of dilute acid hydrolysis and protease digestion was sufficient to solubilize and hydrolyze greater than $80 \%$ of the protein fraction to amino acids suitable for bioconversion [164, 165, 172-174]. Production of a variety of chemicals from algal proteins and carbohydrates, including isopropanol, isobutanol, butanediol, C4 di-acids, amyl alcohol, tertbutyl alcohol, phenylalcohol, and the sesquiterpene, caryophyllene could enhance the economic 
590 sustainability of algal biofuel production. Bench scale batch HTL processing of algal turf at 591 SNL showed conversion yields greater than $40 \%[163,166]$ of the organic fraction of the 592 feedstock into biocrude. The tandem combination of biochemical pre-processing of polyculture 593 algal turf biomass to first convert proteins and carbohydrates to alcohols, followed by HTL 594 processing of the organic residue, has also demonstrated reduction of the $\mathrm{N}$ content in the 595 biocrude to less than $1 \%$. This is in comparison to the $\sim 5 \% \mathrm{~N}$ content in the biocrude produced 596 from the whole algae HTL conversion $[163,166]$. This processing technology, combined with 597 pretreatment to reduce ash content in the wet polyculture material prior to processing, has the 598 potential to increase the flexibility of processing polyculture feedstocks with varying organic 599 composition into fuels. Figure 2 shows the SNL process flow diagram and process yields 600 obtained, based on bench scale test results using polyculture algal turf biomass material having 601 the composition (non-ash components) of $8 \%$ lipids, 39\% protein, 34\% carbohydrate, and 19\% 602 other organics. Also shown at the top of Figure 2 are projections of annual fuel production 603 potential using the two processing pathways, in terms of gasoline gallons equivalent (GGE) fuel 604 per acre, for assumed levels of annual average daily algal turf productivity (AFDW) of $15 \mathrm{~g} \mathrm{~m}^{-2}$ 605 per day and $25 \mathrm{~g} \mathrm{~m}^{-2}$ per day. 606 
2300-3000 GGE/Acre Fuel Potential with Algal Turf Productivity of $15 \mathrm{~g} \mathrm{~m}^{-2} \mathrm{~d}^{-1}$ (AFDW) $\sim 3800-5000$ GGE/Acre Fuel Potential with Algal Turf Productivity of $25 \mathrm{~g} \mathrm{~m}^{-2} \mathrm{~d}^{-1}$ (AFDW)

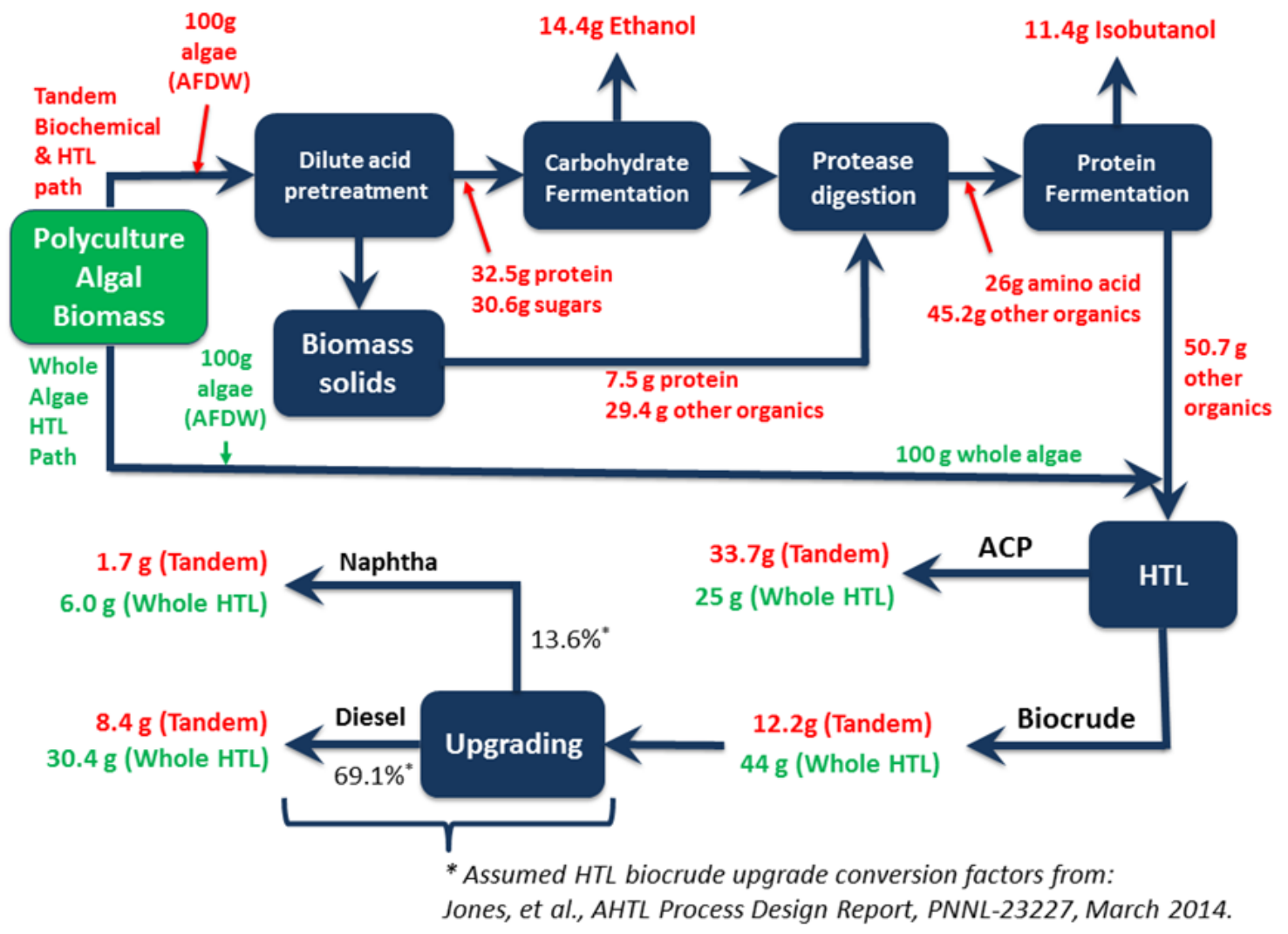

607

608

609

610

611

612

613

614

615

616

617

618

Figure 2. Examples of preliminary product yield and mass balance flows based on SNL evaluation of alternative

biochemical and HTL processing pathways for converting polyculture algal biomass to fuel intermediates and blendstock fuels [166].

\section{SCALE}

The economics at commercial-scale production currently favor algal biomass cultivation in outdoor raceways [176] due to the significantly higher projected costs for biofuel production using closed photobioreactors (PBRs) [5-7], although PBRs are expected to play a role in the production of inoculum in support of maintaining outdoor cultivation at commercial scales [177].

A major challenge for raceway cultivation is the identification of microalgae polycultures that have the potential to exhibit high seasonal or annual biomass productivities in outdoor ponds. 
619 Even if rationally designed polycultures grow well in the laboratory under a given set of

620 incubation conditions (e.g., room temperature and relatively low light intensities), there is no

621 guarantee, even in the absence of predators and invasive species, that the same polycultures will

622 achieve high productivities in outdoor pond cultures that are subjected to a wide range of daily

623 and seasonal water temperature and light fluctuations. Furthermore, a rationally designed

624 polyculture that is cultivated in open outdoor ponds faces the risk of being taken over by local

625 species. This risk may be minimized by assembling the polyculture only with very fast growing

626 and stable strains that are difficult to outcompete by invasive species. Davis et al. (2015)

627 demonstrated the stable biomass growth in a mixed outdoor pond culture of Nannochloropsis

628 salina and Phaeodactylum tricornutum [178]. Similarly, a binary designed culture consisting of

629 fast growing Chlorella and Scenedesmus strains remained free of invasive species in an outdoor

630 pond culture experiment (PNNL unpublished data).

631 Although large-scale microalgae polycultures have been successfully operated in the context

632 of wastewater treatment $[49,179-181]$, these polycultures were not scaled-up from the

633 laboratory; instead they assembled naturally from the available pool of indigenous

634 microorganisms (e.g., cyanobacteria, microalgae, and heterotrophs). Similarly, open polyculture

635 algal turf production using ATS systems for removing excess nutrients in both wastewater and

636 other open surface waters in the environment, which have been contaminated by non-point

637 sources, utilize a naturally assembled mix of indigenous benthic and planktonic microorganisms.

638 The ATS approach is currently being investigated by SNL and other collaborators as potentially

639 being more cost effective than open raceway ponds for the scale-up of algal biomass production

640 for fuels $[163,164,166,167]$. Among the conditions under which this may be possible is where

641 single-pass operation of ATS systems at large scales can achieve sufficiently high annual 
642 average AFDW biomass productivities based on the nutrients and inorganic carbon available in

643 the source water. This would avoid the cost and logistics of needing to add nutrients or

644 supplemental $\mathrm{CO}_{2}$, which would be an operational and cost advantage relative to the

645 recirculating raceway pond approach. However, this requires further investigation and

646 comparative performance assessment before definitive conclusions can be made. High-

647 throughput approaches for evaluating the performance of polycultures representing different

648 combinations of algal strains are needed to advance ecological engineering to a reliable industrial

649 practice.

650 In response to the pressing need for a rational approach to scale up microalgae cultures and to

651 accelerate the transition of laboratory strains to outdoor ponds, two different outdoor pond

652 simulators have been developed and tested recently: the Phenometrics Environmental

653 Photobioreactors ( $\mathrm{ePBR}^{\mathrm{TM}}$ ) and the LED-lighted and temperature-controlled indoor raceway

654 ponds at Pacific Northwest National Laboratory (PNNL). In addition to inherent imprecisions of

655 these indoor pond simulators (as discussed in both the ePBRs and PNNL's LED-lighted and

656 temperature-controlled ponds simulate only the abiotic environment of the outdoor ponds (i.e.,

657 light, temperature, $\mathrm{pH}$, salinity, and mixing) while protecting the cultures, to some degree, from

658 predators and invasive species. Consequently, the biomass productivities measured in these

659 simulated cultures, including polycultures, are likely to reflect the best-case scenario in terms of

660 the expected outdoor pond performance.

661 Assuming that most industrial-scale cultures are grown under conditions where neither

662 essential nutrients (i.e., $\mathrm{N}, \mathrm{P}$, trace-elements, and $\mathrm{CO}_{2}$ ) nor mass-transfer processes (i.e., poor

663 mixing) limit microalgae growth, incident sunlight intensity and pond water temperature that are

664 determined by the climate at the given geographic location are the key environmental factors 
665 affecting biomass productivity. Given these climatic constraints, biomass productivity can be

666 optimized by selecting strains that exhibit high growth rates under the prevailing seasonal light

667 and water temperature conditions.

668 Matching a microalgae strain and its inherent physiological characteristics to the

669 diurnal/seasonal variations in light and temperature conditions in outdoor ponds to optimize

670 biomass productivity is a complex task. To aid in this effort a strain-specific biomass growth

671 model has recently been developed and was used in conjunction with PNNL's biomass

672 assessment tool to generate annual biomass productivity maps for outdoor ponds located at

673 different geographic locations in the United States [84, 185, 186]. The model requires that each

674 strain must be extensively characterized prior to generating maps. The model takes into account

675 a strain's maximum specific growth rate as a function of temperature, light intensity, $\mathrm{pH}$, and

676 salinity. The model also considers the strain's biomass loss rate in the dark as a function of

677 temperature, the average light intensity during the preceding light period, culture depth and

678 biomass concentration [187].

679 In polycultures containing two or more strains, the characteristics of each contributing strain

680 will affect the overall biomass productivity observed in outdoor ponds. For illustration, using a

681 binary co-culture as the simplest case, any of the following differences in physiological

682 characteristics between the two contributing strains is likely to affect not only the overall

683 biomass productivity but also the relative abundance of each strain as a function of time:

684 (a) temperature optimum - the strain that grows faster at a higher temperature will outcompete

685 the strain with the lower temperature optimum during the afternoon hours when the pond water

686 temperatures are the highest; (b) saturating light intensity - assuming both strains have the same

687 maximum specific growth rate at a given temperature, at their respective saturating light 
688 intensity, the strain with the lower saturating light intensity will have an advantage over the 689 competing strain under conditions of low light (i.e., in dense cultures and at dawn and dusk);

690 (c) $\mathrm{pH}$ optimum - the $\mathrm{pH}$ set point and the variations in $\mathrm{pH}$ due to periodic $\mathrm{CO}_{2}$ sparing and 691 subsequent $\mathrm{CO}_{2}$ uptake by the growing culture will determine the relative abundance of each 692 strain based on their respective $\mathrm{pH}$ optima and response functions; (d) salinity optimum - the 693 continuous increase in medium salinity as a result of water evaporation is likely to increase the 694 relative abundance of the strain with the highest salt tolerance; and (e) biomass loss due to dark 695 respiration - the strain that loses the least biomass during the night period will have a 696 competitive advantage and contribute more to the overall biomass productivity of the pond 697 culture. In the presence of continually changing environmental conditions, these differences in 698 physiological characteristics among polyculture strains also explain "the paradox of the 699 plankton" [188], i.e., the ability of highly diverse phototrophic organisms to coexist without ever 700 achieving a stable equilibrium distribution or one specie outcompeting all others, as would be 701 predicted by the competitive exclusion principle [189].

702 Predicting biomass productivity and relative strain abundance of outdoor pond polycultures 703 subjected to diurnal and seasonal light and temperature fluctuations is extremely complex.

704 Consequently, to facilitate rational assembly of engineered polycultures with potential to achieve 705 higher biomass productivities than their respective monocultures, it will be necessary to develop 706 a biomass growth model with experimentally determined physiological input parameters for all 707 contributing strains. This model could be used, in conjunction with the biomass assessment tool, 708 to identify the best geographic location and growth season for each designer polyculture and also 709 select the pond's operational conditions (i.e., pond depth, dilution rate, $\mathrm{pH}$ set point, and salinity 710 range) that are likely to result in optimal seasonal or annual biomass productivities. 


\section{PATH FORWARD}

713 Understanding the interactions among algae, grazers, and microbes; their response to the

714 environment; and their influence on biomass productivity, represent some of the most substantial

715 challenges impeding commercialization of algal biofuels. Searching for general principles

716 governing overyielding, symbiosis, consumer-resource interactions, nutrient recycling, and niche

717 partitioning may simplify the identification of stable and productive communities and

718 environments. Aquatic microbial communities employed for large-scale algal cultivation are

719 likely to become unavoidably diverse through contamination with non-target organisms.

720 Identifying the traits that govern the coexistence and dynamics of species that come together to

721 form a community is the first step toward applying ecological principles toward generating stable 722 and productive bioenergy technologies.

723 Communities of algae grown for biofuel applications (i.e., polycultures) should include

724 species with distinct but complementary ecological roles to utilize resources more effectively

725 than monocultures. This technique has shown promise to outperform monocultures [23, 125,

726 190], resulting in increased biomass production and carbon fixation [31], increased nutrient

727 removal efficiency [10], increased resistance to grazing [10, 23], increased production of carbon

728 storage compounds [37], and enhanced resistance to pathogens [191]. Although, use of

729 polycultures has the potential to limit the effect of grazers, pathogens, and other microbial

730 competitors on algal production, the diversity of these grazers and competitors is broad, meaning

731 use of polycultures alone is not expected to completely limit the ability of these organisms to

732 influence algal production. Therefore, additional crop protection strategies that can be employed 
733 in conjunction with polycultures will likely be necessary to achieve predictable and relatively

734 continuous yields of algal biomass from open cultivation systems.

735 Current techniques for grazer control in algal cultivation systems are limited but are

736 beginning to expand $[17,192,193]$. State-of-the-art approaches include chemical interventions

737 that either selectively kills grazers/pathogens or otherwise provides a selective advantage for the 738 algal crop (i.e., pesticide application) $[17,192,194]$; periodic modulation of chemical conditions 739 in the algal cultivation system filtration (e.g., $\mathrm{pH}$ reduction and $\mathrm{NH}_{3}$ addition) [192, 195]; early

740 detection of grazers and other contaminants to time harvest cycles, thereby limiting grazer effects 741 on productivity $[128,196]$; application of continuous strong selective conditions to limit the 742 growth and viability of unwanted competitors (e.g., hypersaline conditions) [197]; and genetic 743 modification of the algal cultivar to change protein expression, thereby altering palatability of the 744 algal cell [198]. While each of these approaches can reduce the number and impact of grazers, 745 they can also represent unique regulatory or economic hurdles and limit the diversity of the algal 746 strains compatible with each control mechanism.

747 Progress toward large-scale algal biofuel production will likely require a combined approach 748 that incorporates polycultures for enhanced stability and productivity in combination with 749 extrinsic controls on grazing/predation pressure and contaminant introduction. Also required will 750 be further development, refinement, and scale-up of post-harvest pretreatment, processing, and 751 conversion of harvested polyculture algae biomass using chemical, biochemical and/or 752 thermochemical processes for fuel production at commercial scale that can cost-effectively deal 753 with relatively low neutral lipid content and relatively higher inorganic ash content. Improving 754 cultivation and harvesting systems to reduce exogenous ash content in harvested polyculture 755 algae material, especially associated with the ATS approach, is also needed and recommended. 
756

757 


\section{REFERENCES}

[1] J.W. Moody, C.M. McGinty, J.C. Quinn, Global evaluation of biofuel potential from microalgae, Proc. Natl. Acad. Sci. USA, (2014) 8691-8696.

[2] P.T. Pienkos, A. Darzins, The promise and challenges of microalgal-derived biofuels, Biofuels, Bioprod. Biorefin., 3 (2009) 431-440.

[3] J.T. Sheehan, T. Dunahay, J. Benemann, P. Roessler, A look back at the U.S. Department of Energy's Aquatic Species Program-biodiesel from algae, US Dept of Energy's Office of Fuels Development, NREL/TP-580-24190 (1998).

[4] DOE, National algal biofuels technology roadmap, US Department of Energy, Office of Energy Efficiency and Renewable Energy, Biomass Program, 2010.

[5] R. Davis, A. Aden, P.T. Pienkos, Techno-economic analysis of autotrophic microalgae for fuel production, Appl Energy, 88 (2011) 3524-3531.

[6] T.J. Lundquist, I.C. Woertz, N. Quinn, J.R. Benemann, A realistic technology and engineering assessment of algae biofuel production, Energy Biosciences Institute, Berkeley California, 2010.

[7] R. Davis, D. Fishman, E.D. Frank, Renewable diesel from algal lipids: An integrated baseline for cost, emissions, and resource potential from a harmonized model, NREL/TP_5100$55431,2012$.

[8] W. Blanken, M. Cuaresma, R.H. Wijffels, M. Janssen, Cultivation of microalgae on artificial light comes at a cost, Algal Res, 2 (2013) 333-340.

[9] M.Y. Menetrez, An overview of algae biofuel production and potential environmental impact, Environ. Sci. Technol., 46 (2012) 7073-7085. 
780[10] J.B. Shurin, R.L. Abbott, M.S. Deal, G.T. Kwan, E. Litchman, R.C. McBride, S. Mandal, 781 V.H. Smith, Industrial-strength ecology: trade-offs and opportunities in algal biofuel 782 production, Ecol. Lett., 16 (2013) 1393-1404.

783[11] J.W. Richardson, M.D. Johnson, X. Zhang, P. Zemke, W. Chen, Q. Hu, A financial 784 assessment of two alternative cultivation systems and their contributions to algae biofuel 785 economic viability, Algal Res, 4 (2014) 96-104.

786[12] S.M. Vallina, M. Follows, S. Dutkiewicz, J.M. Montoya, P. Cermeno, M. Loreau, Global 787 relationship between phytoplankton diversity and productivity in the ocean, Nature Comm, 5 788 (2014).

789[13] L.T. Carney, J.S. Wilkenfeld, P.D. Lane, O.D. Solberg, Z.B. Fuqua, N.G. Cornelius, S. 790 Gillespie, K.P. Williams, T.M. Samocha, T.W. Lane, Pond Crash Forensics: Presumptive 791 identification of pond crash agents by next generation sequencing in replicate raceway mass 792 cultures of Nannochloropsis salina, Algal Res, 17 (2016) 341-347.

793[14] A. Schmidtke, U. Gaedke, G. Weithoff, A mechanistic basis for underyielding in 794 phytoplankton communities, Ecology, 91 (2010) 212-221.

795[15] P.N. Leao, V. Ramos, M. Vale, J.P. Machado, V.M. Vasconcelos, Microbial community 796 changes elicited by exposure to cyanobacterial allelochemicals, Microb. Ecol., 63 (2012) 8579795.

798[16] P.M. Letcher, S. Lopez, R. Schmieder, P.A. Lee, C. Behnke, M.J. Powell, R.C. McBride, 799 Characterization of Amoeboaphelidium protococcarum, an algal parasite new to the 800 cryptomycota isolated from an outdoor algal pond used for the production of biofuel, PLoS 801 ONE, 8 (2013) e56232. 
[17] R.C. McBride, S. Lopez, C. Meenach, M. Burnett, P.A. Lee, F. Nohilly, C. Behnke, Contamination management in low cost open algae ponds for biofuels production, Ind Biotechnol, 10 (2014) 221-227.

[18] J. Avelino, R. Babin, P. Fernandes, M.t. Hoopen, J.-B. Laurent, K. Naudin, A. Ratnadass, Incorporating plant species diversity in cropping systems for pest and disease risk management, FARM ${ }^{\mathrm{D}}$, Forum for Agricultural Risk Management in Development, 2012.

[19] A.L. Iverson, Linda E. Marın, Katherine K. Ennis, David J. Gonthier, Benjamin T. ConnorBarrie, Jane L. Remfert, B.J. Cardinale, I. Perfecto, Do polycultures promote win-wins or trade-offs in agricultural ecosystem services? A meta-analysis, J. Appl. Ecol., 51 (2014) 1593-1602.

[20] B.J. Cardinale, K. Gross, K. Fritschie, P. Flombaum, J.W. Fox, C. Rixen, J. van Ruijven, P.B. Reich, M. Scherer-Lorenzen, B.J. Wilsey, Biodiversity simultaneously enhances the production and stability of community biomass, but the effects are independent, Ecology, 94 (2013) 1697-1707.

[21] D. Tilman, P.B. Reich, J. Knops, D. Wedin, T. Mielke, C. Lehman, Diversity and productivity in a long-term grassland experiment, Science, 294 (2001) 843-845.

[22] K. Gross, B.J. Cardinale, J.W. Fox, A. Gonzalez, M. Loreau, H.W. Polley, P.B. Reich, J. Van Ruijven, Species richness and the temporal stability of biomass production: A new analysis of recent biodiversity experiments, Am. Nat., 183 (2014) 1-12.

[23] A.A. Corcoran, W.J. Boeing, Biodiversity increases the productivity and stability of phytoplankton communities, PLoS ONE, 7 (2012).

[24] J.B. Shurin, S. Mandal, R.L. Abbott, Trait diversity enhances yield in algal biofuel assemblages, J. Appl. Ecol., 51 (2014) 603-611. 
825[25] D.U. Hooper, E.C. Adair, B.J. Cardinale, J.E. Byrnes, B.A. Hungate, K.L. Matulich, A.

826 Gonzalez, J.E. Duffy, L. Gamfeldt, M.I. O’Connor, A global synthesis reveals biodiversity

827 loss as a major driver of ecosystem change, Nature, 486 (2012) 105-108.

828[26] B.J. Cardinale, J.E. Duffy, A. Gonzalez, D.U. Hooper, C. Perrings, P. Venail, A. Narwani,

829 G.M. Mace, D. Tilman, D.A. Wardle, Biodiversity loss and its impact on humanity, Nature, $830486(2012) 59-67$.

831[27] K. McCann, The diversity-stability debate, Nature, 405 (2000) 228-233.

832[28] S. Wang, M. Loreau, Biodiversity and ecosystem stability across scales in

833 metacommunities, Ecol. Lett., 19 (2016) 510-518.

834[29] D. Tilman, C.L. Lehman, K.T. Thomson, Plant diversity and ecosystem productivity:

835 theoretical considerations, Proc. Natl. Acad. Sci. USA, 94 (1997) 1857-1861.

836[30] A. Parparov, G. Gal, T. Zohary, Quantifying the ecological stability of a phytoplankton

837 community: The Lake Kinneret case study, Ecol. Indicators, 56 (2015) 134-144.

838[31] S. Behl, A. Donval, H. Stibor, The relative importance of species diversity and functional

839 group diversity on carbon uptake in phytoplankton communities, Limnol. Oceanogr., 56

$840 \quad$ (2011) 683-694.

841[32] D.F. Doak, D. Bigger, E. Harding, M. Marvier, R. O'malley, D. Thomson, The statistical

842 inevitability of stability-diversity relationships in community ecology, Am. Nat., 151 (1998)

$843 \quad 264-276$.

844[33] M. Loreau, A. Hector, Partitioning selection and complementarity in biodiversity

845 experiments, Nature, 412 (2001) 72-77.

846[34] X. Irigoien, J. Huisman, R.P. Harris, Global biodiversity patterns of marine phytoplankton 847 and zooplankton, Nature, 429 (2004) 863-867. 
[35] M. Stockenreiter, F. Haupt, A.-K. Graber, J. Seppälä, K. Spilling, T. Tamminen, H. Stibor, Functional group richness: implications of biodiversity for light use and lipid yield in microalgae, J. Phycol., 49 (2013) 838-847.

[36] A. Ianora, A. Miralto, Toxigenic effects of diatoms on grazers, phytoplankton and other microbes: a review, Ecotoxicology, 19 (2010) 493-511.

[37] M. Stockenreiter, A.-K. Graber, F. Haupt, H. Stibor, The effect of species diversity on lipid production by micro-algal communities, J. Appl. Phycol., 24 (2012) 45-54.

[38] J.O. Nalley, M. Stockenreiter, E. Litchman, Community ecology of algal biofuels: complementarity and trait-based approaches, Ind Biotechnol, 10 (2014) 191-201.

[39] B.S. Griffiths, L. Philippot, Insights into the resistance and resilience of the soil microbial community, FEMS Microbiol. Rev., 37 (2013) 112-129.

[40] T. Großkopf, O.S. Soyer, Synthetic microbial communities, Curr. Opin. Microbiol., 18 (2014) 72-77.

[41] D. Beyter, P.-Z. Tang, S. Becker, T. Hoang, D. Bilgin, Y.W. Lim, T.C. Peterson, S. Mayfield, F. Haerizadeh, J.B. Shurin, V. Bafna, R. McBride, Diversity, productivity and stability of an industrial microbial ecosystem, Appl. Environ. Microbiol., 82 (2016) 24942505.

[42] W.H. Adey, K. Loveland, Dynamic aquaria: Building and restoring living ecosystems, Academic Press, Burlington, MA, 2011.

[43] H.D. Laughinghouse, Studies of periphytic algae on algal turf scrubbers ${ }^{\mathrm{TM}}$ along the Chesapeake Bay: community structure, systematics, and influencing factors, Marine Estuarine Environmental Sciences, University of Maryland, College Park, MD, 2012. 
870[44] W.H. Adey, H.D. Laughinghouse, J.B. Miller, L.A.C. Hayek, J.G. Thompson, S. Bertman,

871 K. Hampel, S. Puvanendran, Algal turf scrubber (ATS) floways on the Great Wicomico

872 River, Chesapeake Bay: productivity, algal community structure, substrate and chemistry, J.

873 Phycol., 49 (2013) 489-501.

874[45] W.H. Adey, Algal Turf Scrubber (ATS) algae to energy project: Cleaning rivers while

875 producing biofuels and agricultural and health products, Report to the Lewis Foundation, 876 (2010).

877[46] W. Mulbry, P. Kangas, S. Kondrad, Toward scrubbing the bay: Nutrient removal using 878 small algal turf scrubbers on Chesapeake Bay tributaries, Ecol. Eng., 36 (2010) 536-541. 879[47] W.H. Adey, P.C. Kangas, W. Mulbry, Algal turf scrubbing: Cleaning surface waters with 880 solar energy while producing a biofuel, Bioscience, 61 (2011) 434-441.

881[48] H.N. Sandefur, M.D. Matlock, T.A. Costello, Seasonal productivity of a periphytic algal 882 community for biofuel feedstock generation and nutrient treatment, Ecol. Eng., 37 (2011) $883 \quad 1476-1480$.

884[49] R.J. Craggs, W.H. Adey, B.K. Jessup, W.J. Oswald, A controlled stream mesocosm for 885 tertiary treatment of sewage, Ecol. Eng., 6 (1996) 149-169.

886[50] A.C. Wilkie, W.W. Mulbry, Recovery of dairy manure nutrients by benthic freshwater 887 algae, Bioresour. Technol., 84 (2002) 81-91.

888[51] E. Kebede-Westhead, C. Pizarro, W.W. Mulbry, A.C. Wilkie, Production and nutrient 889 removal by periphyton grown under different loading rates of anaerobically digested flushed 890 dairy manure, J. Phycol., 39 (2003) 1275-1282.

891[52] C. Pizarro, W. Mulbry, D. Blersch, P. Kangas, An economic assessment of algal turf 892 scrubber technology for treatment of dairy manure effluent, Ecol. Eng., 26 (2006) 321-327. 
[53] W. Mulbry, S. Kondrad, C. Pizarro, E. Kebede-Westhead, Treatment of dairy manure effluent using freshwater algae: Algal productivity and recovery of manure nutrients using pilot-scale algal turf scrubbers, Bioresour. Technol., 99 (2008) 8137-8142.

[54] T. Smith, A. Sathish, R. Thompson, R. Sims, Rotating algal biofilm reactor (RABR) for biomass growth and nutrient removal, Algae Biomass SummitOrlando, FL, 2013.

[55] G. Rocap, F.W. Larimer, J. Lamerdin, S. Malfatti, P. Chain, N.A. Ahlgren, A. Arellano, M. Coleman, L. Hauser, W.R. Hess, Z.I. Johnson, M. Land, D. Lindell, A.F. Post, W. Regala, M. Shah, S.L. Shaw, C. Steglich, M.B. Sullivan, C.S. Ting, A. Tolonen, E.A. Webb, E.R. Zinser, S.W. Chisholm, Genome divergence in two Prochlorococcus ecotypes reflects oceanic niche differentiation, Nature, 424 (2003) 1042-1047.

[56] A. Melis, Solar energy conversion efficiencies in photosynthesis: Minimizing the chlorophyll antennae to maximize efficiency, Plant Sci., 177 (2009) 272-280.

[57] E. Stephens, I.L. Ross, Z. King, J.H. Mussgnug, O. Kruse, C. Posten, M.A. Borowitzka, B. Hankamer, An economic and technical evaluation of microalgal biofuels, Nat. Biotechnol., 28 (2010) 126-128.

[58] M. Stomp, J. Huisman, L.J. Stal, H.C. Matthijs, Colorful niches of phototrophic microorganisms shaped by vibrations of the water molecule, The ISME journal, 1 (2007) 271-282.

[59] G. Stephanopoulos, A. Fredrickson, Coexistence of photosynthetic microorganisms with growth rates depending on the spectral quality of light, Bull. Math. Biol., 41 (1979) 525-542. [60] C. van den Hoek, DG Mann, HM Jahns, Algae: An introduction to phycology, Cambridge University Press. Page 623, Cambridge, UK, 1995. 
915[61] M. Stockenreiter, F. Haupt, A.-K. Graber, J. Seppälä, K. Spilling, T. Tamminen, H. Stibor,

916 A. Buschmann, Functional group richness: implications of biodiversity for light use and lipid

917 yield in microalgae, J. Phycol., (2013) n/a-n/a.

918[62] R.C. Pate, Resource requirements for the large-scale production of algal biofuels, Biofuels, 9194 (2013) 409-435.

920[63] R. Pate, G. Klise, B. Wu, Resource demand implications for US algae biofuels production 921 scale-up, Appl Energy, 88 (2011) 3377-3388.

922[64] N. Mallick, Biotechnological potential of immobilized algae for wastewater N, P and metal 923 removal: A review, BioMetals, 15 (2002) 377-390.

924[65] A.J. Dassey, S.G. Hall, C.S. Theegala, An analysis of energy consumption for algal

925 biodiesel production: Comparing the literature with current estimates, Algal Res, 4 (2014)

$92689-95$.

927[66] J. Park, R. Craggs, A. Shilton, Wastewater treatment high rate algal ponds for biofuel 928 production, Bioresour. Technol., 102 (2011) 35-42.

929[67] J. Yang, M. Xu, X. Zhang, Q. Hu, M. Sommerfeld, Y. Chen, Life-cycle analysis on 930 biodiesel production from microalgae: Water footprint and nutrients balance, Bioresour. 931 Technol., 102 (2011) 159-165.

932[68] A. Redfield, On the proportions of organic derivatives in seawater and their relation to the 933 composition of plankton, in: R. Daniel (Ed.) James Johnston Memorial Volume, University 934 Press of Liverpool, Liverpool, 1933, pp. 176-192.

935[69] H. Hillebrand, G. Steinert, M. Boersma, A. Malzahn, C.L. Meunier, C. Plum, R. Ptacnik, 936 Goldman revisited: Faster-growing phytoplankton has lower N : P and lower stoichiometric 937 flexibility, Limnol. Oceanogr., 58 (2013) 2076-2088. 
938 [70] T.M. Lenton, C.A. Klausmeier, Biotic stoichiometric controls on the deep ocean N:P ratio, 939 Biogeosciences, 4 (2007) 353-367.

940 [71] D.L. Sutherland, C. Howard-Williams, M.H. Turnbull, P.A. Broady, R.J. Craggs, Frequency 941 of $\mathrm{CO}_{2}$ supply affects wastewater microalgal photosynthesis, productivity and nutrient 942 removal efficiency in mesocosms: implications for full-scale high rate algal ponds, J. Appl. $943 \quad$ Phycol., 27 (2015) 1901-1911.

944 [72] R.W. Sterner, T. Andersen, J.J. Elser, D.O. Hessen, J.M. Hood, E. McCauley, J. Urabe, 945 Scale-dependent carbon : nitrogen : phosphorus seston stoichiometry in marine and 946 freshwaters, Limnol. Oceanogr., 53 (2008) 1169-1180.

947 [73] R. Ptacnik, A.G. Solimini, T. Andersen, T. Tamminen, P. Brettum, L. Lepisto, E. Willen, S. 948 Rekolainen, Diversity predicts stability and resource use efficiency in natural phytoplankton 949 communities, Proc. Natl. Acad. Sci. U.S.A., 105 (2008) 5134-5138.

950 [74] B.J. Cardinale, Biodiversity improves water quality through niche partitioning, Nature, 472 $951 \quad$ (2011) 86-89.

952 [75] H. Hillebrand, B. Matthiessen, Biodiversity in a complex world: consolidation and progress 953 in functional biodiversity research, Ecol. Lett., 12 (2009) 1405-1419.

954 [76] J.J. Weis, D.S. Madrigal, B.J. Cardinale, Effects of algal diversity on the production of 955 biomass in homogeneous and heterogeneous nutrient environments: A microcosm 956 experiment, PLoS ONE, 3 (2008).

957 [77] I. Woertz, A. Feffer, T. Lundquist, Y. Nelson, Algae grown on dairy and municipal 958 wastewater for simultaneous nutrient removal and lipid production for biofuel feedstock, J. 959 Environ. Eng., 135 (2009) 1115-1122. 
960[78] T. Cai, S.Y. Park, R. Racharaks, Y. Li, Cultivation of Nannochloropsis salina using

961 anaerobic digestion effluent as a nutrient source for biofuel production, Appl Energy, 108

962 (2013) 486-492.

963[79] G.-Y. Kim, Y.-M. Yun, H.-S. Shin, H.-S. Kim, J.-I. Han, Scenedesmus-based treatment of 964 nitrogen and phosphorus from effluent of anaerobic digester and bio-oil production,

965 Bioresour. Technol., 196 (2015) 235-240.

966[80] M. Loreau, C. de Mazancourt, Species synchrony and its drivers: neutral and nonneutral

967 community dynamics in fluctuating environments, Am. Nat., 172 (2008) E48-E66.

968[81] D.A. Vasseur, J.W. Fox, A. Gonzalez, R. Adrian, B.E. Beisner, M.R. Helmus, C. Johnson,

969 P. Kratina, C. Kremer, C. de Mazancourt, Synchronous dynamics of zooplankton competitors

970 prevail in temperate lake ecosystems, Proc. R. Soc. Lond., Ser. B: Biol. Sci., 281 (2014)

97120140633.

972[82] O. Bernard, B. Rémond, Validation of a simple model accounting for light and temperature

973 effect on microalgal growth, Bioresour. Technol., 123 (2012) 520-527.

974[83] P. Waller, R. Ryan, M. Kacira, P. Li, The algae raceway integrated design for optimal

975 temperature management, Biomass Bioenergy, 46 (2012) 702-709.

976[84] M.S. Wigmosta, A.M. Coleman, R.J. Skaggs, M.H. Huesemann, L.J. Lane, National

977 microalgae biofuel production potential and resource demand, Water Resour. Res., 47

978 (2011).

979[85] A.M. Coleman, J.M. Abodeely, R.L. Skaggs, W.A. Moeglein, D.T. Newby, E.R. Venteris,

980 M.S. Wigmosta, An integrated assessment of location-dependent scaling for microalgae

981 biofuel production facilities, Algal Res, 5 (2014) 79-94. 
982 [86] B. Crowe, S. Attalah, S. Agrawal, P. Waller, R. Ryan, J. Van Wagenen, A. Chavis, J.

983 Kyndt, M. Kacira, K.L. Ogden, M. Huesemann, A comparison of Nannochloropsis salina

984 growth performance in two outdoor pond designs: conventional raceways versus the ARID

985 pond with superior temperature management, Int J Chem Eng, 2012 (2012) 9.

986 [87] J. Xu, H. Hu, Screening high oleaginous Chlorella strains from different climate zones,

987 Bioresour. Technol., 144 (2013) 637-643.

988 [88] D.R. Nelson, S. Mengistu, P. Ranum, G. Celio, M. Mashek, D. Mashek, P.A. Lefebvre,

989 New lipid-producing, cold-tolerant yellow-green alga isolated from the Rocky Mountains of

990 Colorado, Biotechnol. Progr., 29 (2013) 853-861.

991 [89] C. Butterwick, S.I. Heaney, J.F. Talling, Diversity in the influence of temperature on the

992 growth rates of freshwater algae, and its ecological relevance, Freshwat. Biol., 50 (2005)

$993 \quad 291-300$.

994 [90] M.K. Thomas, The effect of temperature on the ecology, evolution, and biogeography of 995 phytoplankton, Michigan State University, 2013.

996 [91] E. Litchman, K.F. Edwards, C.A. Klausmeier, M.K. Thomas, Phytoplankton niches, traits

997 and eco-evolutionary responses to global environmental change, Mar. Ecol. Prog. Ser., 470

$998 \quad$ (2012) 235-248.

999 [92] M. Ras, J.-P. Steyer, O. Bernard, Temperature effect on microalgae: a crucial factor for 1000 outdoor production, Rev Env Sci Biotechnol, 12 (2013) 153-164.

1001 [93] S. Schabhüttl, P. Hingsamer, G. Weigelhofer, T. Hein, A. Weigert, M. Striebel, 1002 Temperature and species richness effects in phytoplankton communities, Oecologia, 171 $1003 \quad$ (2013) 527-536. 
1004[94] M.J. Behrenfeld, A.J. Bale, Z.S. Kolber, J. Aiken, P.G. Falkowski, Confirmation of iron 1005 limitation of phytoplankton photosynthesis in the equatorial Pacific Ocean, Nature, 383

1006 (1996) 508-511.

1007[95] E. Keshtacher-Liebso, Y. Hadar, Y. Chen, Oligotrophic bacteria enhance algal growth under 1008 iron-deficient conditions, Appl. Environ. Microbiol., 61 (1995) 2439-2441.

1009[96] S.A. Amin, D.H. Green, M.C. Hart, F.C. Küpper, W.G. Sunda, C.J. Carrano, Photolysis of 1010 iron-siderophore chelates promotes bacterial-algal mutualism, Proc. Natl. Acad. Sci. USA, 1011106 (2009) 17071-17076.

1012[97] M. Sandy, A. Butler, Microbial iron acquisition: marine and terrestrial siderophores, Chem. 1013 Rev., 109 (2009) 4580-4595.

1014[98] M.T. Croft, A.D. Lawrence, E. Raux-Deery, M.J. Warren, A.G. Smith, Algae acquire 1015 vitamin $B_{12}$ through a symbiotic relationship with bacteria, Nature, 438 (2005) 90-93. 1016[99] M.T. Croft, M.J. Warren, A.G. Smith, Algae need their vitamins, Eukaryot. Cell, 5 (2006) $1017 \quad 1175-1183$.

1018[100] M.R. Droop, Vitamins, phytoplankton and bacteria: symbiosis or scavenging?, J. Plankton 1019 Res., 29 (2007) 107-113.

1020[101] E. Kazamia, H. Czesnick, T.T.V. Nguyen, M.T. Croft, E. Sherwood, S. Sasso, S.J. Hodson, 1021 M.J. Warren, A.G. Smith, Mutualistic interactions between vitamin $\mathrm{B}_{12}$-dependent algae and 1022 heterotrophic bacteria exhibit regulation, Environ. Microbiol., 14 (2012) 1466-1476.

1023[102] J. Tate, M.T. Gutierrez-Wing, K. Rusch, M. Benton, The effects of plant growth 1024 substances and mixed cultures on growth and metabolite production of green algae Chlorella 1025 sp.: A review, J. Plant Growth Regul., 32 (2013) 417-428. 
1026 [103] Y. Bashan, G. Holguin, L.E. de-Bashan, Azospirillum-plant relationships: physiological, 1027 molecular, agricultural, and environmental advances (1997-2003), Can. J. Microbiol., 50 $1028 \quad$ (2004) 521-577.

1029 [104] L.E. de-Bashan, A. Trejo, V.A.R. Huss, J.-P. Hernandez, Y. Bashan, Chlorella sorokiniana 1030 UTEX 2805, a heat and intense, sunlight-tolerant microalga with potential for removing 1031 ammonium from wastewater, Bioresour. Technol., 99 (2008) 4980-4989.

1032 [105] S.A. Amin, M.S. Parker, E.V. Armbrust, Interactions between diatoms and bacteria, 1033 Microbiol. Mol. Biol. Rev., 76 (2012) 667-684.

1034 [106] M. Le Chevanton, M. Garnier, G. Bougaran, N. Schreiber, E. Lukomska, J.B. Bérard, E. 1035 Fouilland, O. Bernard, J.P. Cadoret, Screening and selection of growth-promoting bacteria 1036 for Dunaliella cultures, Algal Res, 2 (2013) 212-222.

1037 [107] M. Sapp, A. Schwaderer, K. Wiltshire, H.-G. Hoppe, G. Gerdts, A. Wichels, Species1038 specific bacterial communities in the phycosphere of microalgae?, Microb. Ecol., 53 (2007) $1039 \quad 683-699$.

1040 [108] Y. Park, K.-W. Je, K. Lee, S.-E. Jung, T.-J. Choi, Growth promotion of Chlorella 1041 ellipsoidea by co-inoculation with Brevundimonas sp. isolated from the microalga, $1042 \quad$ Hydrobiologia, 598 (2008) 219-228.

1043 [109] K. Watanabe, N. Takihana, H. Aoyagi, S. Hanada, Y. Watanabe, N. Ohmura, H. Saiki, H. 1044 Tanaka, Symbiotic association in Chlorella culture, FEMS Microbiol. Ecol., 51 (2005) 187$1045 \quad 196$.

1046 [110] S. Janson, A.N. Rai, B. Bergman, Intracellular cyanobiont Richelia intracellularis:

1047 ultrastructure and immuno-localization of phycoerythrin, nitrogenase, Rubisco and glutamine 1048 synthetase, Mar. Biol., 124 (1995) 1-8. 
1049[111] R.A. Foster, J.P. Zehr, Characterization of diatom-cyanobacteria symbioses on the basis of 1050 nifH, hetR and 16S rRNA sequences, Environ. Microbiol., 8 (2006) 1913-1925.

1051[112] R.A. Foster, M.M.M. Kuypers, T. Vagner, R.W. Paerl, N. Musat, J.P. Zehr, Nitrogen

1052 fixation and transfer in open ocean diatom-cyanobacterial symbioses, Isme Journal, 5 (2011) $1053 \quad 1484-1493$.

1054[113] A.W. Thompson, R.A. Foster, A. Krupke, B.J. Carter, N. Musat, D. Vaulot, M.M.M.

1055 Kuypers, J.P. Zehr, Unicellular cyanobacterium symbiotic with a single-celled eukaryotic 1056 alga, Science, 337 (2012) 1546-1550.

1057[114] L. Rodolfi, G. Chini Zittelli, N. Bassi, G. Padovani, N. Biondi, G. Bonini, M.R. Tredici, 1058 Microalgae for oil: Strain selection, induction of lipid synthesis and outdoor mass cultivation 1059 in a low-cost photobioreactor, Biotechnol. Bioeng., 102 (2009) 100-112.

1060[115] S. Mandal, N. Mallick, Microalga Scenedesmus obliquus as a potential source for biodiesel 1061 production, Appl. Microbiol. Biotechnol., 84 (2009) 281-291.

1062[116] Q. Hu, M. Sommerfeld, E. Jarvis, M. Ghirardi, M. Posewitz, M. Seibert, A. Darzins, 1063 Microalgal triacylglycerols as feedstocks for biofuel production: perspectives and advances, 1064 Plant J, 54 (2008) 621-639.

1065[117] S. Mandal, N. Mallick, Waste utilization and biodiesel production by the green microalga 1066 Scenedesmus obliquus, Appl. Environ. Microbiol., 77 (2011) 374-377.

1067[118] G. Knothe, Dependence of biodiesel fuel properties on the structure of fatty acid alkyl 1068 esters, Fuel Process. Technol., 86 (2005) 1059-1070.

1069[119] R.O. Dunn, G. Knothe, Oxidative stability of biodiesel in blends with jet fuel by analysis 1070 of oil stability index, J. Am. Oil Chem. Soc., 80 (2003) 1047-1048. 1071[120] K. Feris, unpublished data. 
1072 [121] U. Sommer, F. Sommer, B. Santer, C. Jamieson, M. Boersma, C. Becker, T. Hansen, 1073 Complementary impact of copepods and cladocerans on phytoplankton, Ecol. Lett., 4 (2001) $1074 \quad 545-550$.

1075 [122] B.W. Ibelings, A. De Bruin, M. Kagami, M. Rijkeboer, M. Brehm, E.V. Donk, Host 1076 parasite interactions between freshwater phytoplankton and chytrid fungi (Chytridiomycota), 1077 J. Phycol., 40 (2004) 437-453.

1078 [123] Y.H. Kang, J.D. Kim, B.H. Kim, D.S. Kong, M.S. Han, Isolation and characterization of a 1079 bio-agent antagonistic to diatom, Stephanodiscus hantzschii, J. Appl. Microbiol., 98 (2005) $1080 \quad 1030-1038$.

1081 [124] V.H. Smith, T. Crews, Applying ecological principles of crop cultivation in large-scale 1082 algal biomass production, Algal Res, 4 (2014) 23-34.

1083 [125] J.B. Shurin, Dispersal limitation, invasion resistance, and the structure of pond 1084 zooplankton communities, Ecology, 81 (2000) 3074-3086.

1085 [126] A.J. Horne, C.R. Goldman, Limnology, McGraw-Hill New York1994.

1086 [127] D.M. Blersch, P.C. Kangas, W.W. Mulbry, Turbulence and nutrient interactions that 1087 control benthic algal production in an engineered cultivation raceway, Algal Res, 2 (2013) $1088 \quad 107-112$.

1089 [128] L.T. Carney, S.S. Reinsch, P.D. Lane, O.D. Solberg, L.S. Jansen, K.P. Williams, J.D. 1090 Trent, T.W. Lane, Microbiome analysis of a microalgal mass culture growing in municipal 1091 wastewater in a prototype OMEGA photobioreactor, Algal Res, 4 (2014) 52-61.

1092 [129] Y. Hoffman, C. Aflalo, A. Zarka, J. Gutman, T.Y. James, S. Boussiba, Isolation and 1093 characterization of a novel chytrid species (phylum Blastocladiomycota), parasitic on the 1094 green alga Haematococcus, Mycol. Res., 112 (2008) 70-81. 
1095[130] H. Hillebrand, B.J. Cardinale, Consumer effects decline with prey diversity, Ecol. Lett., 7 1096 (2004) 192-201.

1097[131] J.E. Duffy, Biodiversity and ecosystem function: the consumer connection, Oikos, 99 $1098 \quad$ (2002) 201-219.

1099[132] P. Kratina, M. Vos, B.R. Anholt, Species diversity modulates predation, Ecology, 88 $1100 \quad$ (2007) 1917-1923.

1101[133] V. Ördög, W. Stirk, R. Lenobel, M. Bancířová, M. Strnad, J. Van Staden, J. Szigeti, L. 1102 Németh, Screening microalgae for some potentially useful agricultural and pharmaceutical 1103 secondary metabolites, J. Appl. Phycol., 16 (2004) 309-314.

1104[134] F. Keesing, R.D. Holt, R.S. Ostfeld, Effects of species diversity on disease risk, Ecol. Lett., 11059 (2006) 485-498.

1106[135] K. LoGiudice, R.S. Ostfeld, K.A. Schmidt, F. Keesing, The ecology of infectious disease: 1107 effects of host diversity and community composition on Lyme disease risk, Proc. Natl. Acad. 1108 Sci. USA, 100 (2003) 567-571.

1109[136] L. Jiang, Negative selection effects suppress relationships between bacterial diversity and 1110 ecosystem functioning, Ecology, 88 (2007) 1075-1085.

1111[137] P. Cermeno, T. Rodriguez-Ramos, M. Dornelas, F.G. Figueiras, E. Maranon, I.G. Teixeira, 1112 S.M. Vallina, Species richness in marine phytoplankton communities is not correlated to 1113 ecosystem productivity, Mar. Ecol. Prog. Ser., 488 (2013) 1-9.

1114[138] J.B. Shurin, S. Mandal, R.L. Abbott, M. Cadotte, Trait diversity enhances yield in algal 1115 biofuel assemblages, J. Appl. Ecol., 51 (2014) 603-611. 
[139] P.A. Venail, A. Narwani, K. Fritschie, M.A. Alexandrou, T.H. Oakley, B.J. Cardinale, The influence of phylogenetic relatedness on species interactions among freshwater green algae in a mesocosm experiment, J. Ecol., 102 (2014) 1288-1299.

[140] J.C. Quinn, C. Demill, Integration of experimental system with engineering process modeling for sustainability assessment., $6^{\text {th }}$ International Conference on Algal Biomass, Biofuels \& BioproductsSan Diego, CA, June 26-29, 2016.

[141] NRC, Sustainable development of algal biofuels in the United States, National Academies Press, Washington DC, (2012 prepublication release).

[142] J. McGowen, G. Dirks, ATP ${ }^{3}$ Algae testbed, public-private partnership, 2015 DOE BETO Algae Platform ReviewWashington, DC, March 25, 2015.

[143] P. Biller, A.B. Ross, S.C. Skill, A. Lea-Langton, B. Balasundaram, C. Hall, R. Riley, C.A. Llewellyn, Nutrient recycling of aqueous phase for microalgae cultivation from the hydrothermal liquefaction process, Algal Res, 1 (2012) 70-76.

[144] P.E. Savage, Algae under pressure and in hot water, Science, 338 (2012) 1039-1040.

[145] G.W. Roberts, M.O.P. Fortier, B.S.M. Sturm, S.M. Stagg-Williams, Promising pathway for algal biofuels through wastewater cultivation and hydrothermal conversion, Energy Fuels, 27 (2013) 857-867.

[146] U. Jena, K. Das, Comparative evaluation of thermochemical liquefaction and pyrolysis for bio-oil production from microalgae, Energy Fuels, 25 (2011) 5472-5482.

[147] W.-T. Chen, Y. Zhang, J. Zhang, G. Yu, L.C. Schideman, P. Zhang, M. Minarick, Hydrothermal liquefaction of mixed-culture algal biomass from wastewater treatment system into bio-crude oil, Bioresour. Technol., 152 (2014) 130-139. 
1138[148] H. Li, Z. Liu, Y. Zhang, B. Li, H. Lu, N. Duan, M. Liu, Z. Zhu, B. Si, Conversion

1139 efficiency and oil quality of low-lipid high-protein and high-lipid low-protein microalgae via

1140 hydrothermal liquefaction, Bioresour. Technol., 154 (2014) 322-329.

1141[149] N. Neveux, A. Yuen, C. Jazrawi, M. Magnusson, B. Haynes, A. Masters, A. Montoya, N.

1142 Paul, T. Maschmeyer, R. de Nys, Biocrude yield and productivity from the hydrothermal

1143 liquefaction of marine and freshwater green macroalgae, Bioresour. Technol., 155 (2014)

1144 334-341.

1145[150] S.B. Jones, Y. Zhu, D.M. Anderson, R.T. Hallen, D.C. Elliott, A.J. Schmidt, K.O.

1146 Albrecht, T.R. Hart, M.G. Butcher, C. Drennan, Process design and economics for the

1147 conversion of algal biomass to hydrocarbons: whole algae hydrothermal liquefaction and

1148 upgrading, Pacific Northwest National Laboratory, PNNL-23227, 2014.

1149[151] P.J. Valdez, M.C. Nelson, H.Y. Wang, X.N. Lin, P.E. Savage, Hydrothermal liquefaction

1150 of Nannochloropsis sp.: Systematic study of process variables and analysis of the product

1151 fractions, Biomass Bioenergy, 46 (2012) 317-331.

1152[152] E.D. Frank, A. Elgowainy, J. Han, Z. Wang, Life cycle comparison of hydrothermal

1153 liquefaction and lipid extraction pathways to renewable diesel from algae, Mitigation and

1154 Adaptation Strategies for Global Change, 18 (2013) 137-158.

1155[153] D.C. Elliott, P. Biller, A.B. Ross, A.J. Schmidt, S.B. Jones, Hydrothermal liquefaction of

1156 biomass: Developments from batch to continuous process, Bioresour. Technol., 178 (2015)

1157 147-156.

1158[154] G. Yu, Hydrothermal liquefaction of low-lipid microalgae to produce bio-crude oil,

1159 Agricultural and Biological Engineering, University of Illinois at Urbana-Champaign,

1160 Urbana, Illinois, 2012. 
1161 [155] P. Zhang, Characterization of biofuel from diatoms via hydrothermal liquefaction,

1162 Agricultural and Biological Engineering, University of Illinois at Urbana-Champaign,

1163 Urbana, Illinois, 2014.

1164 [156] W.-T. Chen, Y. Zhang, J. Zhang, L. Schideman, G. Yu, P. Zhang, M. Minarick, Co-

1165 liquefaction of swine manure and mixed-culture algal biomass from a wastewater treatment

1166 system to produce bio-crude oil, Appl Energy, 128 (2014) 209-216.

1167 [157] W.-T. Chen, J. Ma, Y. Zhang, C. Gai, W. Qian, Physical pretreatments of wastewater algae

1168 to reduce ash content and improve thermal decomposition characteristics, Bioresour.

1169 Technol., 169 (2014) 816-820.

1170 [158] A.A. Peterson, F. Vogel, R.P. Lachance, M. Froling, J.M.J. Antal, J.W. Tester,

1171 Thermochemical biofuel production in hydrothermal media: A review of sub- and

1172 supercritical water technologies, Energy \& Environmental Science, 1 (2008) 32-65.

1173 [159] C. Jazrawi, P. Biller, A.B. Ross, A. Montoya, T. Maschmeyer, B.S. Haynes, Pilot plant

1174 testing of continuous hydrothermal liquefaction of microalgae, Algal Res, 2 (2013) 268-277.

1175 [160] R. Cherad, J.A. Onwudili, P. Biller, P.T. Williams, A.B. Ross, Hydrogen production from

1176 the catalytic supercritical water gasification of process water generated from hydrothermal

1177 liquefaction of microalgae, Fuel, 166 (2016) 24-28.

1178 [161] A. Sathish, R.C. Sims, Biodiesel from mixed culture algae via a wet lipid extraction

1179 procedure, Bioresour. Technol., 118 (2012) 643-647.

1180 [162] L. Xiu, B. Saydah, P. Eranki, L. Colosi, B. Mitchell, J. Rhodes, A. Clarens, Pilot-scale data

1181 provide enhanced estimates of the life cycle energy and emissions profile of algae biofuels

1182 produced via hydrothermal liquefaction, Biosource Technol, 148 (2013) 163-171. 
1183[163] R.C. Pate, et al., Algal Turf to Fuel (ATF): System overview and preliminary assessment 1184 of the production of biofuels from chemical, biochemical, and thermochemical processing 1185 and conversion of benthic polyculture biomass produced by algal turf cultivation, 2014 1186 Algae Biomass SummitSan Diego, CA, 2014.

1187[164] Ron C Pate, RW Davis, A George, T Drennan, P Pacheco, BC Wu, W Adey, D Calahan, 1188 M Zivojnovich, JC Quinn, J. Hoffman, Update on algal turf to fuel (ATF), Algae Biomass 1189 SummitWashington D.C., 2015.

1190[165] R. Davis, George, A., Lane, T., Pate, R., And Wu. B.,, Tandem biochemical and 1191 thermochemical conversion of mixed algal biomass. Provisional Patent Application, 1192 SD13207/DOE S\#139021, Filed June 25, 2014.

1193[166] R.C. Pate, SNL AOP Project 1.3.1.103: Polyculture Conversion and Analysis, Presentation 1194 for BETO Algae Technology Area Peer Review, (2015, Alexandria, VA.). 1195[167] J Hoffman, RC Pate, T Drennan, J. Quinn, Techno-economic assessment of open 1196 microalgae production systems, (Submitted to Energy).

1197[168] R.C. Pate, B. Wu, R. Davis, A. George, P. Pacheco, T. Drennen, B. Fogleman, B. Jeffers, 1198 W. Adey, D. Calahan, M. Zivojnovich, A. Siccardi, J.C. Quinn, Updated project status and 1199 feasibility assessment of polyculture algal turf to fuels, $6^{\text {th }}$ International Conference on Algal 1200 Biomass, Biofuels \& BioproductsSan Diego, CA, June 26-29, 2016.

1201[169] D. Elliot, D. Anderson, Personal communication at Pacific Northwest National Laboratory 1202 on July $27,2016$.

1203[170] C. Miao, M. Chakraborty, S.L. Chen, Impact of reaction conditions on the simultaneous 1204 production of polysaccharides and bio-oil from heterotrophically grown Chlorella 
sorokiniana by a unique sequential hydrothermal liquefaction process, Bioresour. Technol., 110 (2012) 617-627.

1207

1208

1209

1210

1211

1212

1213

1214

1215

1216

1217

1218

1219

1220

1221

1222

1223

1224

1225

1226

[171] Y.-X. Huo, K.M. Cho, J.G.L. Rivera, E. Monte, C.R. Shen, Y. Yan, J.C. Liao, Conversion of proteins into biofuels by engineering nitrogen flux, Nat. Biotechnol., 29 (2011) 346-351.

[172] R.W. Davis, Protein Fermentation, DOE-BETO 2015 Peer ReviewAlexandria, VA, March 24, 2014.

[173] W Wu, RW Davis, BC Wu, Improved algal biofuel yield through bioconversion of proteins to mixed alcohols and sesquiterpenes, 37th symposium on Biotechnology for Fuels and ChemicalsSan Diego, CA, April 26-30, 2015.

[174] RW Davis, W Wu, M Tran-Gyamfi, TW Lane, RC Pate, BC Wu, Comprehensive bioconversion of algae to liquid fuels and intermediate value products, Algae Biomass SummitWashington D.C., 2015.

[175] J.L. Faeth, P.J. Valdez, P.E. Savage, Fast hydrothermal liquefaction of Nannochloropsis sp. to produce biocrude, Energy Fuels, 27 (2013) 1391-1398.

[176] Y. Chisti, Biodiesel from microalgae, Biotechnol. Adv., 25 (2007) 294-306.

[177] R. Davis, J. Markham, C. Kinchin, N. Grundi, E.C.D. Tan, D. Humbird, Process design and economics for the production of algal biomass: Algal biomass production in open pond, National Renewable Energy Laboratory, NREL/TP-5100-64772., 2016.

[178] R.W. Davis, A.J. Siccardi III, N.D. Huysman, N.B. Wyatt, J.C. Hewson, T.W. Lane, Growth of mono- and mixed cultures of Nannochloropsis salina and Phaeodactylum tricornutum on struvite as a nutrient source, Bioresour. Technol., 198 (2015) 577-585.

[179] B. Chen, Patterns of thermal limits of phytoplankton, J. Plankton Res., (2015). 
1227[180] R. Craggs, S. Heubeck, T. Lundquist, J. Benemann, Algal biofuels from wastewater 1228 treatment high rate algal ponds, Water Sci. Technol., 63 (2011) 660-665.

1229[181] J. Park, R. Craggs, Wastewater treatment and algal production in high rate algal ponds 1230 with carbon dioxide addition, Water Sci. Technol., 61 (2010) 633-639.

1231[182] B.F. Lucker, C.C. Hall, R. Zegarac, D.M. Kramer, The environmental photobioreactor 1232 (ePBR): An algal culturing platform for simulating dynamic natural environments, Algal 1233 Res, 6 (2014) 242-249.

1234[183] M. Huesemann, B. Crowe, A. Chavis, T. Valentine, T. Piers, M. Wigmosta, T. Dale, S. 1235 Twary, A. Barry, R. Yoshida, Simulation of outdoor pond cultures using indoor LED-lighted 1236 and temperature-controlled raceway ponds and Phenometrics ${ }^{\mathrm{TM}}$ photobioreactors, Algal 1237 Research, Submitted 2016, (2016).

1238[184] NAABB, Full Final Report, Section III, (2014) 38.

1239[185] M.H. Huesemann, B. Crowe, P. Waller, A. Chavis, S. Hobbs, S. Edmundson, M.

1240 Wigmosta, A validated model to predict microalgae growth in outdoor pond cultures

1241 subjected to fluctuating light intensities and water temperatures, Algal Res, 13 (2016) 195-

1242206.

1243[186] M. Huesemann, J. Van Wagenen, T. Miller, A. Chavis, S. Hobbs, B. Crowe, A screening 1244 model to predict microalgae biomass growth in photobioreactors and raceway ponds, 1245 Biotechnol. Bioeng., 110 (2013) 1583-1594.

1246[187] S. Edmundson, M. Huesemann, The dark side of algae cultivation: A comparison of 1247 biomass loss at night in three photosynthetic algae, Chlorella sorokiniana, Nannochloropsis 1248 salina and Picochlorum sp., Algal Res, 12 (2015) 470-476.

1249[188] G.E. Hutchinson, The paradox of the plankton, Am. Nat., (1961) 137-145. 
1250 [189] G. Hardin, The competitive exclusion principle, Science, 131 (1960) 1292-1297.

1251 [190] J.J. Stachowicz, R.B. Whitlatch, R.W. Osman, Species diversity and invasion resistance in 1252 a marine ecosystem, Science, 286 (1999) 1577-1579.

1253 [191] E. Kazamia, D.C. Aldridge, A.G. Smith, Synthetic ecology-A way forward for sustainable 1254 algal biofuel production?, J. Biotechnol., 162 (2012) 163-169.

1255 [192] H. Wang, W. Zhang, L. Chen, J. Wang, T. Liu, The contamination and control of 1256 biological pollutants in mass cultivation of microalgae, Bioresour. Technol., 128 (2013) 745$1257 \quad 750$.

1258 [193] J.G. Day, Grazers: the overlooked threat to the sustained production of future algal 1259 biofuels, Biofuels, Bioprod. Biorefin., 4 (2013) 459-461.

1260 [194] T.W. Snell, F.H. Hoff, Fertilization and male fertility in the rotifer Brachionus plicatilis, $1261 \quad$ Hydrobiologia, 147 (1987) 329-334.

1262 [195] E.W. Becker, Microalgae: biotechnology and microbiology, Cambridge University Press 12631994.

1264 [196] J.G. Day, S.P. Slocombe, M.S. Stanley, Overcoming biological constraints to enable the 1265 exploitation of microalgae for biofuels, Bioresour. Technol., 109 (2012) 245-251.

1266 [197] F. Post, L. Borowitzka, M. Borowitzka, B. Mackay, T. Moulton, The protozoa of a 1267 Western Australian hypersaline lagoon, Hydrobiologia, 105 (1983) 95-113.

1268 [198] R. Simkovsky, E.F. Daniels, K. Tang, S.C. Huynh, S.S. Golden, B. Brahamsha, 1269 Impairment of O-antigen production confers resistance to grazing in a model amoeba1270 cyanobacterium predator-prey system, Proc. Natl. Acad. Sci. USA, 109 (2012) 16678-16683. 